\title{
Death to the Cobb-Douglas Production Function? \\ A Meta-Analysis of the Capital-Labor Substitution Elasticity*
}

\author{
Sebastian Gechert ${ }^{\mathrm{a}}$, Tomas Havranek ${ }^{\mathrm{b}}$, Zuzana Irsova ${ }^{\mathrm{b}}$, Dominika Kolcunova ${ }^{\mathrm{b}, \mathrm{c}}$ \\ ${ }^{a}$ Macroeconomic Policy Institute, Düsseldorf \\ ${ }^{\mathrm{b}}$ Charles University, Prague \\ ${ }^{\mathrm{c}}$ Czech National Bank
}

November 14, 2019

\begin{abstract}
We show that the large elasticity of substitution between capital and labor estimated in the literature on average, 0.9 , can be explained by three factors: publication bias, use of aggregated data, and omission of the first-order condition for capital. The mean elasticity conditional on the absence of publication bias, disaggregated data, and inclusion of information from the first-order condition for capital is 0.3 . To obtain this result, we collect 3,186 estimates of the elasticity reported in 121 studies, codify 71 variables that reflect the context in which researchers produce their estimates, and address model uncertainty by Bayesian and frequentist model averaging. We employ nonlinear techniques to correct for publication bias, which is responsible for at least half of the overall reduction in the mean elasticity from 0.9 to 0.3 . Our findings also suggest that a failure to normalize the production function leads to a substantial upward bias in the estimated elasticity. The weight of evidence accumulated in the empirical literature emphatically rejects the Cobb-Douglas specification.
\end{abstract}

Keywords: Elasticity of substitution, capital, labor, publication bias, model uncertainty

JEL Codes: $\quad$ D24, E23, O14

\section{Introduction}

A key parameter in economics is the elasticity of substitution between capital and labor. Among other things, the size of the elasticity has practical consequences for monetary policy, as Figure 1 illustrates. In the SIGMA model used by the Federal Reserve Board, the effectiveness of interest rate changes in steering inflation doubles when one assumes the elasticity to equal 0.9 instead of 0.5, yielding wildly different policy implications. We choose the SIGMA model for the illustration because, as one of very few models employed by central banks, it actually

${ }^{*}$ An online appendix with data and code is available at meta-analysis.cz/sigma. Corresponding author: Tomas Havranek, tomas.havranek@ies-prague.org 
Figure 1: The elasticity of substitution matters for monetary policy

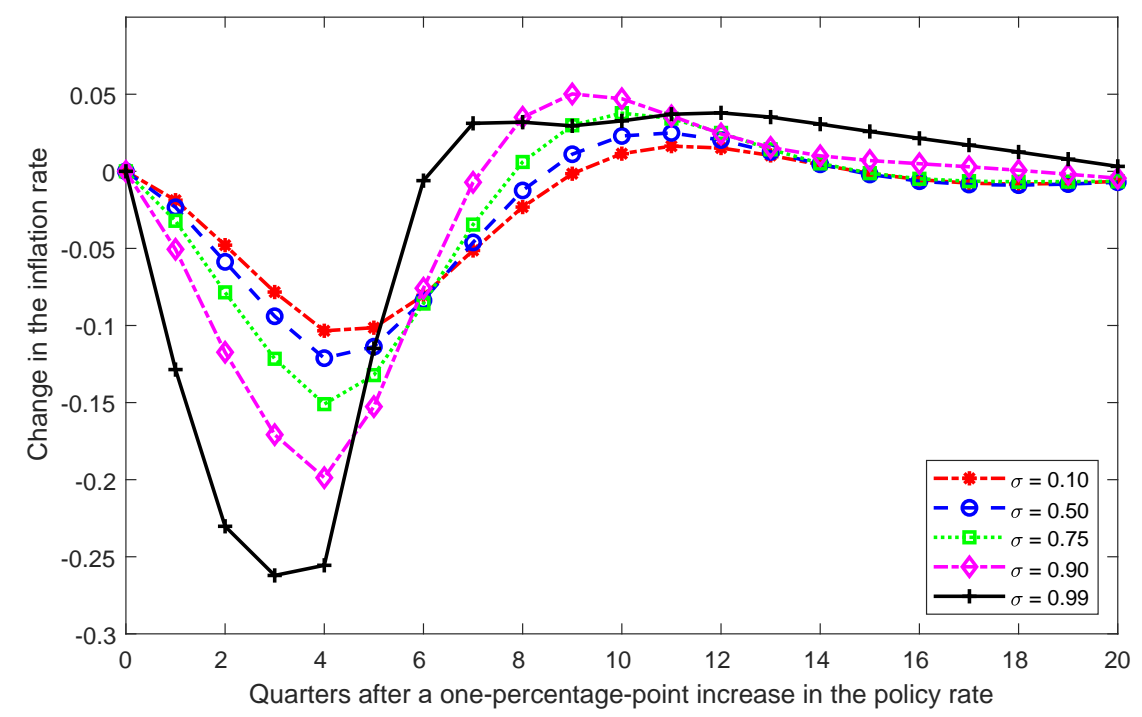

Notes: The figure shows simulated impulse responses of inflation to a monetary policy shock. We use the SIGMA model of Erceg et al. (2008) developed for the Federal Reserve Board and vary the value of the capital-labor substitution elasticity while leaving other parameters at their original values. The model does not have a stable solution for $\sigma$ larger than one.

allows for different values of the elasticity of substitution. Almost all models use the convenient simplification of the Cobb-Douglas production function, which implicitly assumes that the elasticity equals one. If the true elasticity is smaller, these models overstate the strength of monetary policy and should imply a more aggressive campaign of interest rate cuts in response to a recession (Chirinko \& Mallick, 2017, make a related argument). In this paper we show that the Cobb-Douglas specification is at grave odds with the empirical evidence on the elasticity.

Aside from convenience, the other reason for the widespread use of the Cobb-Douglas production function is that, at first sight, empirical investigations into the value of the elasticity have produced many central estimates close to 1 . When each study gets the same weight, the mean elasticity reported in the literature reaches 0.9 - at least based on our attempt to collect all published estimates, in total 3,186 coefficients from 121 studies. But we show that the picture is seriously distorted by publication bias. After correcting for the bias, the mean reported elasticity shrinks to 0.5 . This correction alone can imply halving the effectiveness of monetary policy in a structural model, as shown by Figure 1. Moreover, some data and method choices affect the estimated elasticity systematically. If one agrees that sector-level data dominate more aggregated country- or state-level data and that including information from the first-order condition for capital dominates ignoring it, the implied mean estimate further decreases to 0.3. Thus we recommend 0.3 for the calibration of the elasticity, consistent with burying the Cobb-Douglas production function.

The finding of strong publication bias predominates in our results. The bias arises when different estimates have a different probability of being reported depending on sign and statistical significance. The identification builds on the fact that almost all econometric techniques used to estimate the elasticity assume that the ratio of the estimate to its standard error has 
a symmetrical distribution, typically a $t$-distribution. So the estimates and standard errors should represent independent quantities. But if statistically significant positive estimates are preferentially selected for publication, large standard errors (given by noise in data or imprecision in estimation) will become associated with large estimates. Because empirical economists command plenty of degrees of freedom, a large estimate of the elasticity can always emerge if the researcher looks for it long enough, and an upward bias in the literature arises. A useful analogy appears in McCloskey \& Ziliak (2019), who liken publication bias to the Lombard effect in biology: speakers increase their effort in the presence of noise. Apart from linear techniques based on the Lombard effect, we employ recently developed methods by Ioannidis et al. (2017), Andrews \& Kasy (2019), Bom \& Rachinger (2019), and Furukawa (2019), which account for the potential nonlinearity between the standard error and selection effort.

The studies in our dataset do not estimate a single population parameter; rather, the precise interpretation of the elasticity differs depending on the context in which authors derive their results. We collect 71 variables that reflect the different contexts and find that our conclusions regarding publication bias hold when we control for context. Because of the richness of the literature on the elasticity of substitution, we face substantial model uncertainty with many controls and address it by using Bayesian (Eicher et al., 2011; Steel, 2019) and frequentist (Hansen, 2007; Amini \& Parmeter, 2012) model averaging. We investigate how the estimated elasticities depend on publication bias and the data and methods used in the analysis. Our results suggest that three factors drive the heterogeneity in the literature: publication bias (the size of the standard error), aggregation of input data (industry-level vs. country-level), and identification approach (whether or not information from the first-order condition for capital is ignored). In addition, the normalization of the production function used in recent studies typically brings much smaller reported elasticities, by 0.3 on average. We also find that different assumptions regarding technical change have little systematic effect on the reported elasticity and that estimations using systems of equations tend to deliver results similar to those of singleequation approaches focused on the first-order condition for capital.

As the bottom line of our analysis, we construct a synthetic study that uses all the estimates reported in the literature but assigns more weight to those that are arguably better specified. The result represents a mean estimate implied by the literature but conditional on the absence of publication bias, use of best-practice methodology, and other aspects of quality (such as publication in a leading journal). In this way we obtain an elasticity of 0.3 , the best guess we can make about the parameter underpinned by half a century of accumulated empirical evidence. Defining best-practice methodology, of course, is subjective, and different authors will have different preferences on the various aspects of study design. But to arrive at 0.3 , it is enough to hold two preferences: i) industry-level data are superior to more aggregated countrylevel data and ii) including information from the first-order condition for capital is superior to ignoring it. To put these numbers into perspective, we once again turn to the Fed's SIGMA model, which employs a value of 0.5 for the elasticity of substitution (Erceg et al., 2008). This calibration corresponds to the mean estimate in the literature corrected for publication bias, 
without discounting any estimates based on data and methodology. The model employed by the Bank of Finland (Kilponen et al. 2016), on the other hand, uses the elasticity of 0.85, which is close to the mean estimate in the literature without correcting for publication bias. The calibration closest to our final result is that of Cantore et al. (2015), who use a prior of 0.4. Their posterior estimate is even lower, though, at below 0.2 .

The elasticity of substitution between capital and labor is central to a host of problems aside from monetary policy. Our understanding of long-run growth depends on the value of the elasticity (Solow, 1956). The sustainability of growth in the absence of technological change is contingent on whether or not the elasticity of substitution exceeds one (Antras, 2004). Klump \& de La Grandville (2000) suggest that a larger elasticity in a country results in higher per capita income at any stage of development. Turnovsky (2002) argues that a smaller elasticity leads to faster convergence. The explanation for the decline of the labor share in income during the recent decades that was put forward by Piketty (2014) and Karabarbounis \& Neiman (2013) holds only when the elasticity surpasses one. Cantore et al. (2014) show how the effect of technology shocks on hours worked is sensitive to the elasticity. Nekarda \& Ramey (2013) argue that the countercyclicality of the price markup over marginal cost also depends on the elasticity of substitution. In addition, the elasticity represents an important parameter in analyzing the effects of fiscal policies, including the effect of corporate taxation on capital formation, and in determining optimal taxation of capital (Chirinko, 2002).

The remainder of the paper is structured as follows: Section 2 briefly discusses how the elasticity of substitution is estimated; Section 3 describes how we collect estimates of the elasticity from primary studies and provides a bird's-eye view of the data; Section 4 examines publication bias; Section 5 investigates the drivers of heterogeneity in the reported elasticities and calculates the mean elasticity implied by best practice in the literature; and Section 6 concludes the paper. Appendix A and Appendix B describe the bias-correction techniques designed by Furukawa (2019) and Andrews \& Kasy (2019). Appendix C shows summary statistics of the variables that reflect study context, Appendix D presents robustness checks, and Appendix E includes the list of studies from which we extract estimates. The data and code are available in an online appendix at meta-analysis.cz/sigma.

\section{Estimating the Elasticity}

To set the stage for data collection and identification of factors driving heterogeneity in results, we provide a short description of the most common approaches to estimating the elasticity of substitution between capital and labor. The concept was introduced by Hicks (1932) and almost simultaneously and independently by Robinson (1933), whose more popular definition treats the elasticity as a percentage change of the ratio of two production factors divided by the percentage change of the ratio of their marginal products. Under perfect competition, both 
inputs are paid their marginal products, so the elasticity of substitution can be written as

$$
\sigma=\frac{d(K / L) /(K / L)}{d(w / r) /(w / r)}=-\frac{d \log (K / L)}{d \log (r / w)}
$$

where $K$ and $L$ denote capital and labor, $r$ is the rental price of capital, and $w$ is the wage rate. Under a quasiconcave production function the elasticity attains any number in the interval $(0, \infty)$. If $\sigma=0$, capital and labor are perfect complements, always used in a fixed proportion in the Leontief production function. If the elasticity lies in the interval $(0,1)$, capital and labor form gross complements. If $\sigma=1$, the production function becomes Cobb-Douglas, and the relative change in quantity becomes exactly proportional to the relative change in prices. If the elasticity lies in the interval $(1, \infty)$, capital and labor form gross substitutes.

Although the concept of the elasticity of substitution was introduced in the 1930s, empirical estimates were only enabled by an innovation that came more than 20 years later: the introduction of the constant elasticity of substitution (CES) production function by Solow (1956), later popularized by Arrow et al. (1961). The CES production function can be written as

$$
Y_{t}=C\left[\pi\left(A_{t}^{K} K_{t}\right)^{\frac{\sigma-1}{\sigma}}+(1-\pi)\left(A_{t}^{L} L_{t}\right)^{\frac{\sigma-1}{\sigma}}\right]^{\frac{\sigma}{\sigma-1}}
$$

where $\sigma$ denotes the elasticity of substitution, $K$ and $L$ are capital and labor, $C$ is an efficiency parameter, and $\pi$ is a distributional parameter. The fraction $\frac{\sigma-1}{\sigma}$ is often labeled as $\rho$, a transformation of the elasticity called the substitution parameter. $A_{t}^{K}$ and $A_{t}^{L}$ denote the level of efficiency of the respective inputs, and variations in $A_{t}^{K}$ and $A_{t}^{L}$ over time reflect capital- and labor-augmenting technological change. When $A_{t}^{K}=A_{t}^{L}=A_{t}$, technological change becomes Hicks-neutral, which means that the marginal rate of substitution does not change when an innovation occurs.

The CES production function is nonlinear in parameters, and in contrast to the CobbDouglas case, a simple analytical linearization does not emerge. Thus the CES production function can be estimated (i) in its nonlinear form, (ii) in a linearized form as suggested by Kmenta (1967), or (iii) by using first-order conditions (FOCs). Kmenta (1967) introduced a logarithmized version of Equation 2 with Hicks-neutral technological change:

$$
\log Y_{t}=\log C+\frac{\sigma}{\sigma-1} \log \left[\pi K_{t}^{\frac{\sigma-1}{\sigma}}+(1-\pi) L_{t}^{\frac{\sigma-1}{\sigma}}\right]
$$

and then applied a second-order Taylor series expansion to the term $\log [\cdot]$ around the point $\sigma=1$ to arrive at a function linear in $\sigma$ :

$$
\log Y_{t}=\log C+\pi \log K_{t}+(1-\pi) \log L_{t}-\frac{(\sigma-1) \pi(1-\pi)}{2 \sigma}\left(\log K_{t}-\log L_{t}\right)^{2} .
$$

Estimation of $\sigma$ via first-order conditions was first suggested by Arrow et al. (1961). The underlying assumptions involve constant returns to scale and fully competitive factor and product 
markets. The FOC with respect to capital can be written as follows:

$$
\log \left(\frac{Y_{t}}{K_{t}}\right)=\sigma \log \left(\frac{1}{\pi}\right)+(1-\sigma) \log \left(A_{t}^{K} C\right)+\sigma \log \left(\frac{r_{t}}{p_{t}}\right) .
$$

Consequently, the FOC with respect to labor implies

$$
\log \left(\frac{Y_{t}}{L_{t}}\right)=\sigma \log \left(\frac{1}{1-\pi}\right)+(1-\sigma) \log \left(A_{t}^{L} C\right)+\sigma \log \left(\frac{w_{t}}{p_{t}}\right)
$$

where $p$ is the price of the output. Both conditions can be combined to yield

$$
\log \left(\frac{K_{t}}{L_{t}}\right)=\sigma \log \left(\frac{\pi}{1-\pi}\right)+(\sigma-1) \log \left(\frac{A_{t}^{K}}{A_{t}^{L}}\right)+\sigma \log \left(\frac{w_{t}}{r_{t}}\right) .
$$

In a similar way, one can derive FOCs with respect to the labor share $(w L) / Y$, capital share $(r K) / Y$, or their reversed counterparts. The FOCs can be estimated separately as single equations, within a system of two or three FOCs, and as a system of FOCs coupled with a nonlinear or linearized CES production function. The latter approach (also called a supply-side system approach) has become especially popular in recent studies. León-Ledesma et al. (2010) assert that using the supply-side system approach dominates one-equation estimation, especially when coupled with cross-equation restrictions and normalization, which was suggested by de La Grandville (1989) and Klump \& de La Grandville (2000). After scaling technological progress so that $A_{0}^{K}=A_{0}^{L}=1$, the normalized production function can be written as

$$
Y_{t}=Y_{0}\left[\pi_{0}\left(\frac{A_{t}^{K} K_{t}}{K_{0}}\right)^{\frac{\sigma-1}{\sigma}}+\left(1-\pi_{0}\right)\left(\frac{A_{t}^{L} L_{t}}{L_{0}}\right)^{\frac{\sigma-1}{\sigma}}\right]^{\frac{\sigma}{\sigma-1}},
$$

where $\pi_{0}=r_{0} K_{0} /\left(r_{0} K_{0}+w_{0} L_{0}\right)$ denotes the capital income share evaluated at the point of normalization. The point of normalization can be defined, for instance, in terms of sample means.

Though the aforementioned approaches to estimating the elasticity dominate the literature, we also consider other approaches, in particular the translog production function. The translog function is quadratic in the logarithms of inputs and outputs and provides the second-order approximation to any production frontier (omitting now subscript $t$ for ease of exposition):

$$
\log Y=\log \alpha_{0}+\sum_{i} \alpha_{i} \log X_{i}+\frac{1}{2} \sum_{i} \sum_{j} \alpha_{i j} \log X_{i} \log X_{j}
$$

where $\alpha_{0}$ denotes the state of technological knowledge, and $X_{i}$ and $X_{j}$ are inputs, in our case capital and labor. The translog production frontier provides a wider set of options for substitution and transformation patterns than a frontier based on the CES production function. Due to the duality principle, researchers often employ the translog cost function instead: 


$$
\log C=\alpha_{0}+\theta_{1} \log Y+\frac{1}{2} \theta_{2}(\log Y)^{2}+\sum_{i} \beta_{i} \log P_{i}+\frac{1}{2} \sum_{i} \sum_{j} \epsilon_{i j} \log P_{i} \log P_{j}+\sum_{i} \delta_{i} \log P_{i} \log Y,
$$

where $C$ denotes total costs, $i=K, L$, and $P_{i}$ is input factor price (that is, $w$ and $r$ ). Using Sheppard's lemma, the following cost share functions can be derived:

$$
S_{i}=\beta_{i}+\sum_{i} \epsilon_{i j} \log P_{j}+\delta_{i} \log Y
$$

where $S_{i}$ denotes the share of the $i$-th factor in total costs. In this case, Allen partial elasticities of substitution are most often estimated and are defined as

$$
\sigma_{i j}=\frac{\gamma_{i j}+S_{i} S_{j}}{S_{i} S_{j}}
$$

We include estimates from all of the abovementioned specifications, as each of them provides a measure of the elasticity of substitution between capital and labor, broadly defined. Then we control for the various aspects of the context in which researchers obtain their estimates. These aspects are presented and discussed in detail later in Section 5 , while the following section describes the dataset of the estimated elasticities.

\section{Data}

We use Google Scholar to search for studies estimating the elasticity. Google's algorithm goes through the full text of studies, thus increasing the coverage of suitable published estimates, irrespective of the precise formulation of the study's title, abstract, and keywords. Our search query, available in the online appendix, is calibrated so that it yields the best-known relevant studies among the first hits. We examine the first 500 papers returned by the search. In addition, we inspect the lists of references in these studies and their Google Scholar citations to check whether we can find usable studies not captured by our baseline search - a method called "snowballing" in the literature on research synthesis. We terminate the search on August 1, 2018, and do not add any new studies beyond that date.

To be included in our dataset, a study must satisfy three criteria. First, at least one estimate in the study must be directly comparable with the estimates described in Section 2 . Second, the study must be published. This criterion is mostly due to feasibility since even after restricting our attention to published studies the dataset involves a manual collection of hundreds of thousands of data points. Moreover, we expect published studies to exhibit higher quality on average and to contain fewer typos and mistakes in reporting their results. Note that the inclusion of unpublished papers is unlikely to alleviate publication bias (Rusnak et al. 2013): researchers write their papers with the intention to publish 11 Third, the study must

\footnotetext{
${ }^{1} \mathrm{~A}$ more precise label for publication bias is therefore "selective reporting", but we use the former, more common one to maintain consistency with previous studies on the topic, such as DeLong \& Lang (1992), Card \& Krueger (1995), and Ashenfelter \& Greenstone (2004).
} 
report standard errors or other statistics from which the standard error can be computed. If the elasticity is not reported directly, but can be derived from the presented results, we use the delta method to approximate the standard error. Omitting the estimates with approximated standard errors does not change our results up to a second decimal place.

Using the search algorithm and inclusion criteria described above, we collect 3,186 estimates of the elasticity of substitution from 121 studies. To our knowledge, this makes our paper the largest meta-analysis conducted in economics so far: Doucouliagos \& Stanley (2013), for example, survey dozens of meta-analyses and find that the largest one uses 1,460 estimates. Ioannidis et al. (2017) report that the mean number of estimates used in economics metaanalyses is 400 . The literature on the elasticity of substitution is vast, with a long tradition spanning six decades and more than 100 countries. The list of the studies we include in the dataset (we call them "primary studies") is available in Appendix E. Out of the 121 studies, 39 are published in the five leading journals in economics. Altogether, they have received more than 20,000 citations in Google Scholar, highlighting the importance of the topic.

Figure 2: Distribution of the estimated elasticities

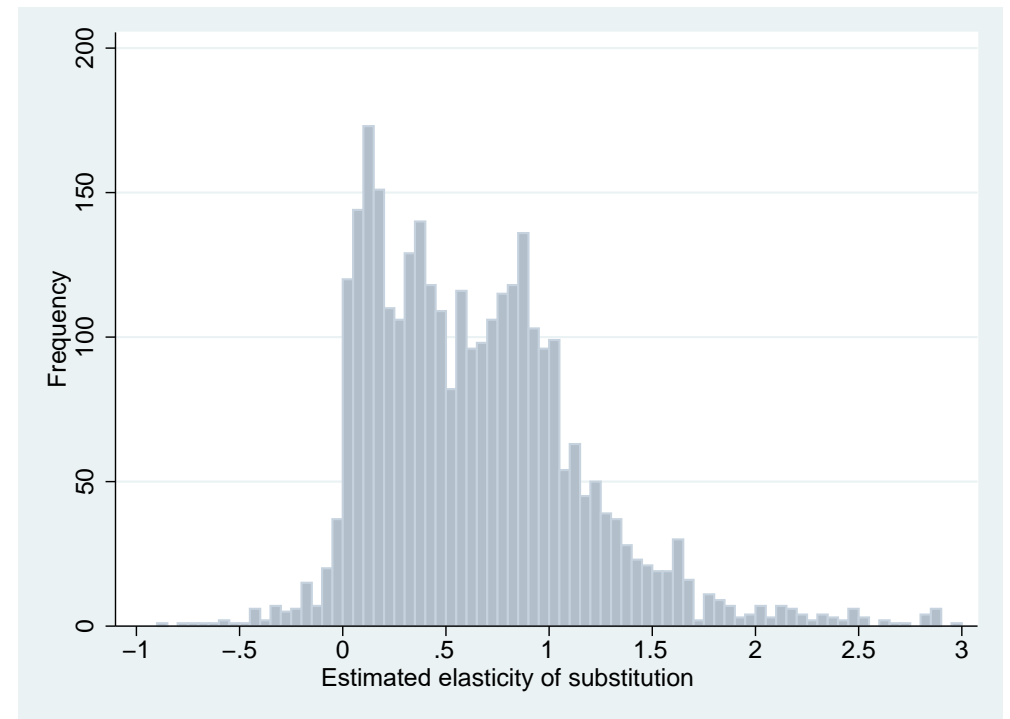

Notes: Estimates smaller than -1 and larger than 3 are excluded from the figure for ease of exposition but included in all statistical tests.

The mean reported estimate of the elasticity of substitution is 0.9 when we give the same weight to each study; that is, when we weight the estimates by the inverse of the number of observations reported per study. A simple mean of all estimates is 0.8. We consider the weighted mean to be more informative, because the simple mean is driven by studies that report many estimates, typically the results of robustness checks, and we see little reason to place more weight on such studies. For both such constructed means, in any case, the deviation from the CobbDouglas specification is not dramatic, and one could use the mean estimate from the literature as a justification of why the Cobb-Douglas production function presents a solid approximation 
of the data. We will argue that such an interpretation of the data misleads the reader because of publication bias and misspecifications in the literature.

Figure 2 shows the distribution of the estimates in our dataset. Curiously, the distribution is bimodal, with peaks near 0 and slightly under 1, pointing to strong and systematic heterogeneity among the estimates. Three-quarters of the estimates lie between 0 and 1, 21\% are greater than one, and only $4 \%$ attain a theoretically implausible negative value. At first sight it is apparent that a researcher wishing to calibrate her structural model can find some empirical justification for any value of the elasticity between 0 and 1.5. There are a few extreme outliers in the data, thus we winsorize the estimates at the $5 \%$ level (our main results hold with different winsorization levels). In Figure 3 we show the box plot of the estimates. Not only do elasticities vary across studies, but also within studies. Most studies report at least some estimates close to 1 , giving further (but superficial, as we will show later) credence to the Cobb-Douglas specification.

Apart from the estimates of $\sigma$ and their standard errors, we collect 71 variables that capture the context in which different estimates are obtained. In consequence, we had to collect more than 220,000 data points from primary studies - a laborious but complex exercise that cannot be delegated to research assistants. The data were collected by two of the coauthors of this paper, each of whom then double-checked random portions of the data collected by the other coauthor in order to minimize potential mistakes arising from manually coding so many entries. The entire process took seven months, and the final dataset is available in the online appendix. Out of the 71 variables that we collect, 50 are included in the baseline model, while the rest only appear in the subsamples of the data for which they apply.

A casual look at the estimates reveals systematic differences among the reported elasticities derived from different data and identified using different methodologies. The most striking patterns are shown in Figure 4. For instance, while the mean of the estimates coming from the first-order condition for capital is 0.4 , for the first-order condition for labor the mean is twice as much. The mean of the elasticities based on time series data is 0.5 , while for cross-sectional data it reaches 0.8. Estimates based on industry-level data appear to be systematically smaller than those based on country-level data, and elasticities presented for individual industries are on average larger than estimates aggregated at the level of the entire economy. These patterns explain the bimodality of the overall histogram presented in Figure 2. Nevertheless, at this point we cannot be sure whether the differences are fundamental or whether they reflect correlations with other factors. A detailed analysis of heterogeneity is available in Section 5. Some of the differences among the estimates can also be attributable to publication bias, an issue to which we turn next.

\section{Publication Bias}

Theory and intuition provides little backing for a zero or negative elasticity of substitution between capital and labor, so it seems natural to discard such estimates. Previous researchers (most prominently, Ioannidis et al., 2017) have shown that such a censoring distorts inference 
Figure 3: Estimates vary both across and within studies

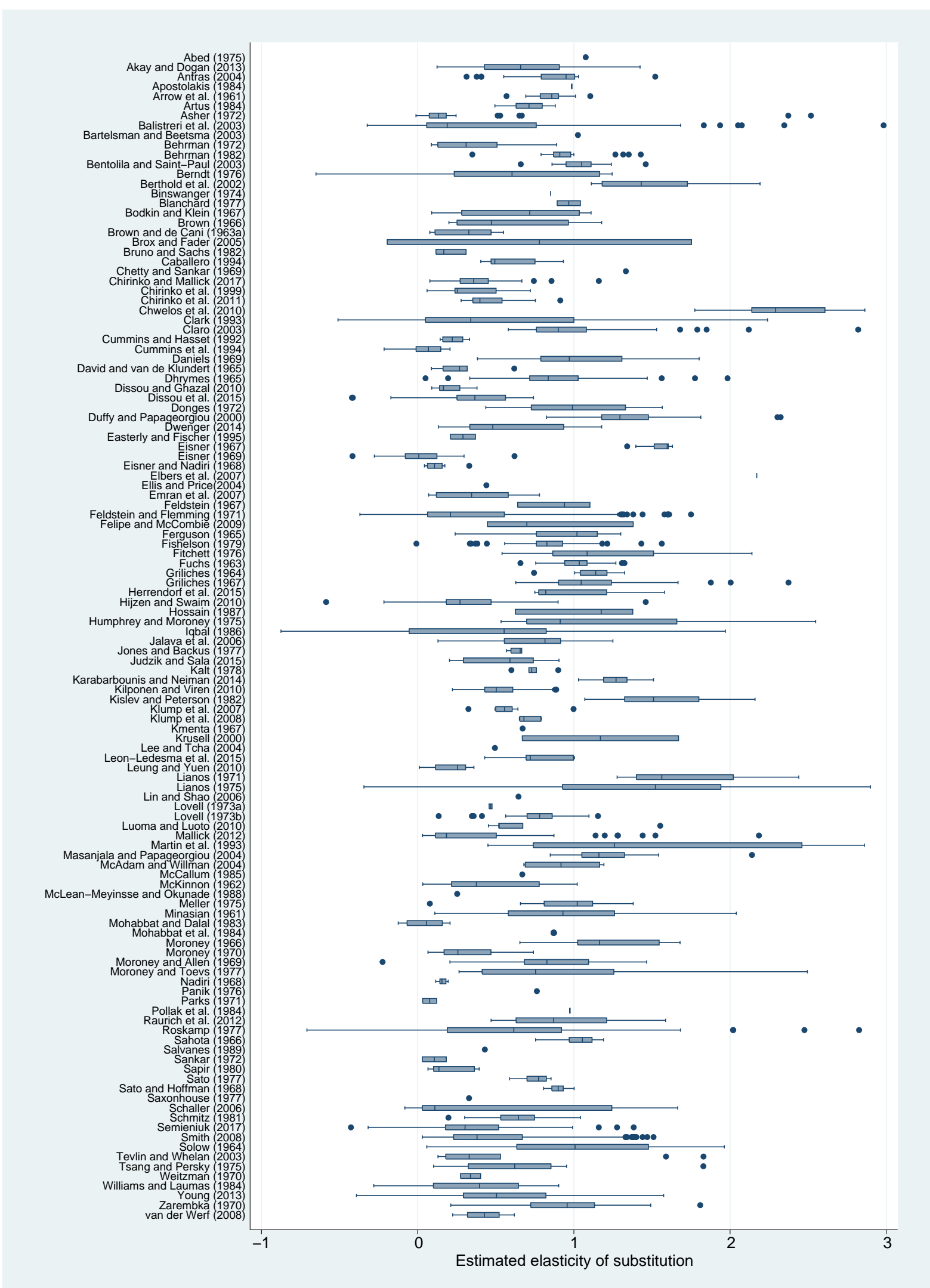

Notes: The figure shows a box plot of the estimates of the elasticity of substitution reported in individual studies. The box shows interquartile range (P25-P75) and the median highlighted. Whiskers cover (P25 - 1.5*interquartile range) to $(\mathrm{P} 75+1.5 *$ interquartile range). The dots are remaining (outlying) estimates. Estimates smaller than -1 and larger than 3 are excluded from the figure for ease of exposition but included in all statistical tests. 
drawn from the literature, and here we document that publication bias is strong in the case of the elasticity of substitution. Even when the true elasticity is positive in every single estimation context, given sufficient noise in data and methods both negative and zero (statistically insignificant) estimates will appear. For each individual author who obtains such estimates, it makes little sense to focus on them; it will bring her study closer to the truth if she finds and highlights a specification that yields a clearly positive elasticity. The problem is that noise in data and methods will also produce estimates that are much larger than the true effect, and such estimates are hard to identify: no upper threshold symmetrical to zero exists that would tell the researcher the estimates are implausible. If many small imprecise estimates are discarded but many large imprecise estimates are reported, an upward bias arises in the literature. Ioannidis et al. (2017) document that the typical exaggeration due to publication bias in economics is twofold. We find it remarkable that no study has addressed potential publication bias in the literature on the elasticity of substitution between capital and labor, one of the most important parameters in economics.

Figure 4: Prima facie patterns in the data

(a) Estimation form

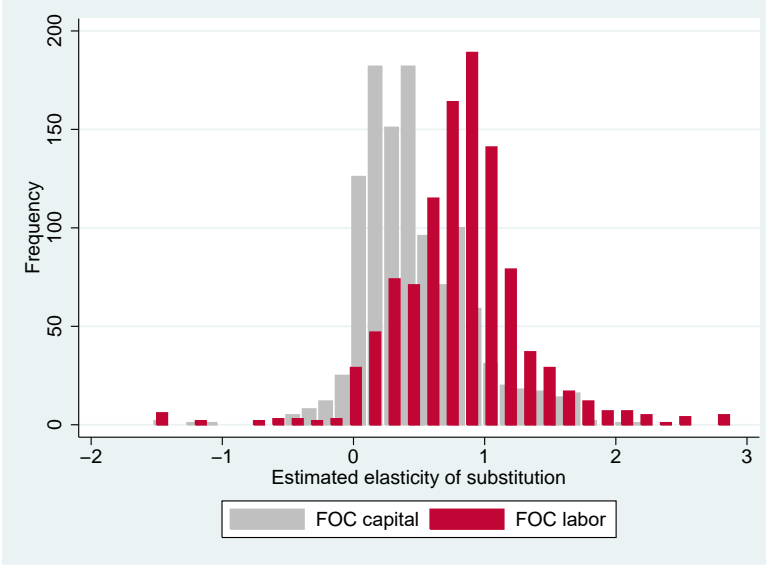

(c) Data dimension

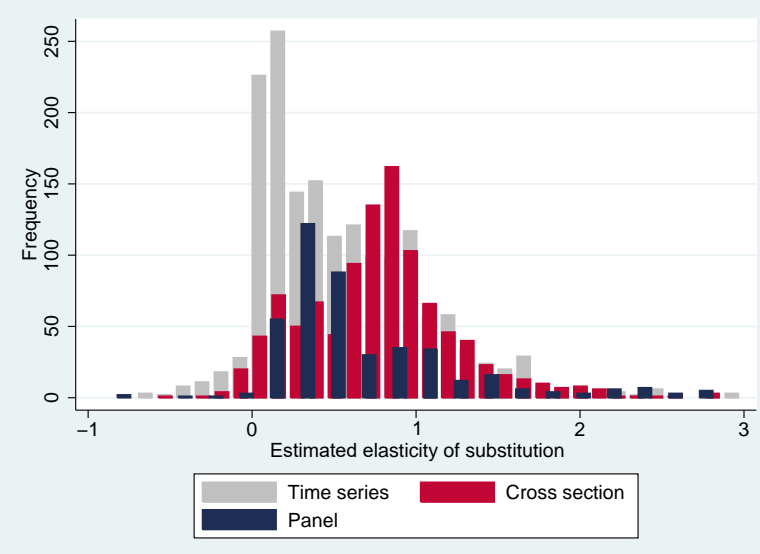

(b) Results aggregation

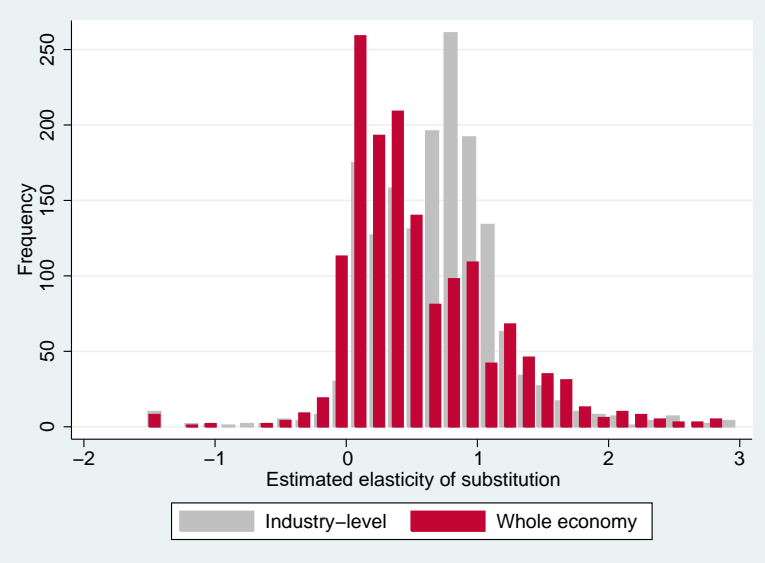

(d) Input data

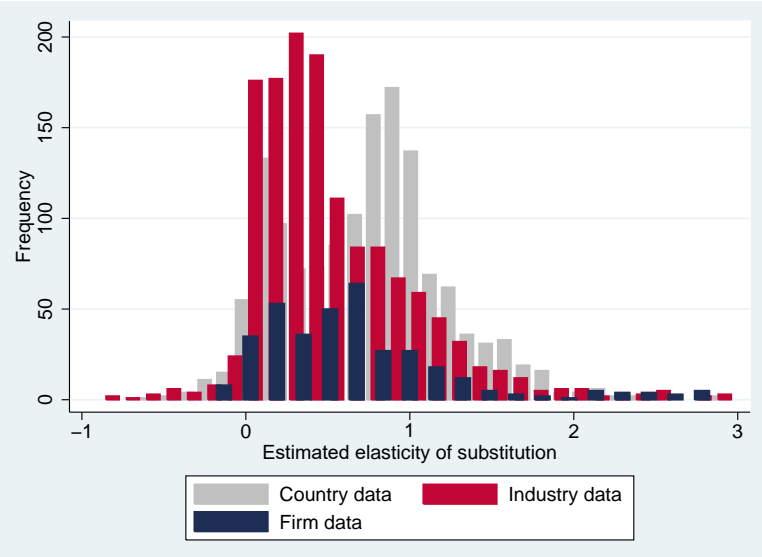

Notes: $\mathrm{FOC}=$ first-order condition. Estimates smaller than -1 and larger than 3 are excluded from the figure for ease of exposition but included in all statistical tests. 
Figure 5: Negative estimates of the elasticity are underreported
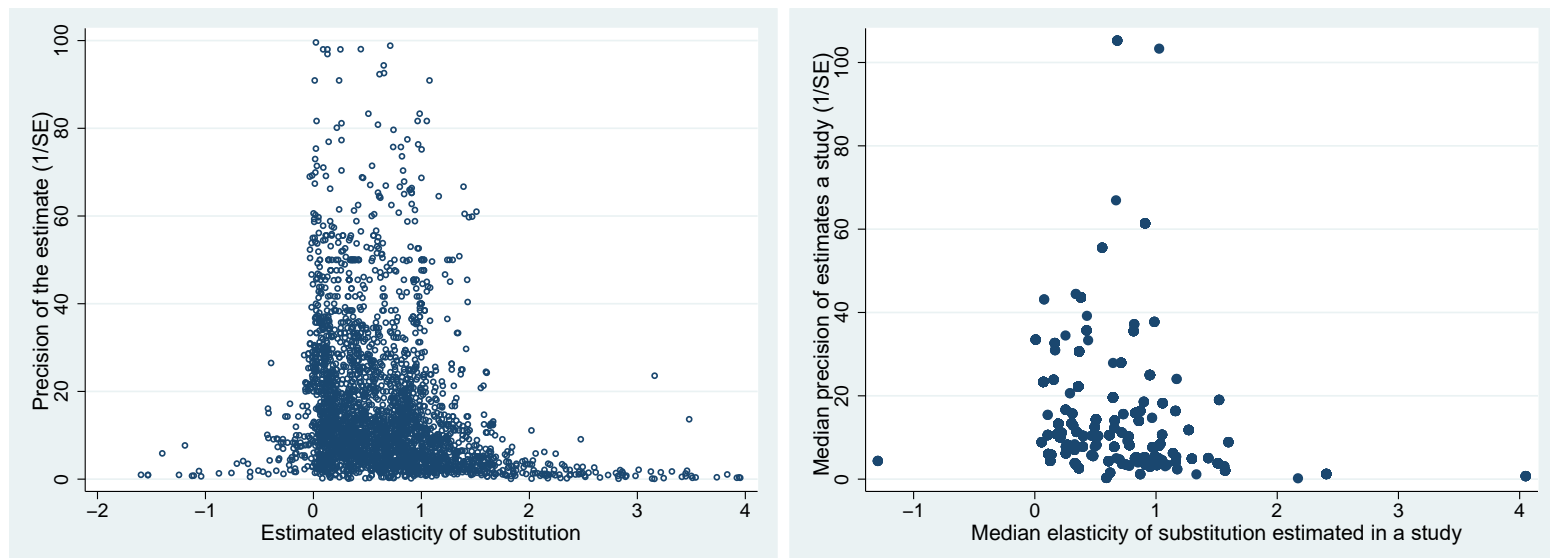

Notes: In the absence of publication bias the scatter plot should resemble an inverted funnel symmetrical around the most precise estimates. The left panel shows all estimates, the right panel shows median estimates from each study. Estimates smaller than -2 and larger than 4 are excluded from the figure for ease of exposition but included in all statistical tests.

Figure 5 provides a graphical illustration of the mechanism outlined in the previous paragraph. In the scatter plot the horizontal axis measures the magnitude of the estimated elasticities, and the vertical axis measures their precision. In the absence of publication bias, the scatter plot will form an inverted funnel: the most precise estimates will lie close to the true mean elasticity, imprecise estimates will be more dispersed, and both small and large imprecise estimates will appear with the same frequency. (The scatter plot is thus typically called a funnel plot, Stanley \& Doucouliagos 2010.) The figure shows the predicted funnel shape, still with plenty of heterogeneity at the top - but also shows asymmetry. For the funnel to be symmetrical, and hence consistent with the absence of publication bias, we should observe many more reported negative and zero estimates.

To identify publication bias numerically, we refer to the analogy with the Lombard effect mentioned in the Introduction: other things being equal, under publication bias authors will increase their effort (specification search) in response to noise (imprecision resulting from data or methodology). Thus publication bias is consistent with finding a correlation between estimates of the elasticity and their standard errors. In contrast, if there is no bias, there should be no correlation, because the properties of the techniques used to obtain the elasticity ensure that the ratio of the estimate to its standard error has a $t$-distribution. It follows that estimates and standard errors should be statistically independent quantities. In any case, the intercept in the regression of the estimated elasticities on their standard errors can be interpreted as the mean elasticity corrected for potential publication bias (Stanley, 2005). It represents the mean elasticity conditional on the standard error approaching zero, and because in this specification publication bias forms a linearly increasing function of the standard error, the intercept measures the corrected estimate. The coefficient on the standard error measures publication bias and can be thought of as a test of the asymmetry of the funnel plot. So we have

$$
\hat{\sigma}_{i j}=\sigma_{0}+\gamma S E\left(\hat{\sigma}_{i j}\right)+u_{i j}
$$


where $\hat{\sigma}$ is the $i$-th estimated elasticity in study $j, \gamma$ denotes the intensity of publication bias, and $\sigma_{0}$ represents the mean elasticity corrected for the bias.

In Table 1 we report the results of several specifications based on Equation 13. We cluster standard errors at both the study and the country level, as estimates are unlikely to be independent within these two dimensions; our implementation of two-way clustering follows Cameron et al. (2011). We also report wild bootstrap confidence intervals (Cameron et al., 2008). In all specifications we find a statistically significant and positive coefficient on the standard error (publication bias) and a significant and positive intercept (the mean elasticity corrected for the bias). After correcting for publication bias, the mean elasticity drops from 0.9 to 0.5 . The result is robust across all specifications with the exception of one, which suggests an even stronger bias and smaller corrected elasticity.

Table 1: Linear tests of funnel asymmetry suggest publication bias

\begin{tabular}{lcccccc}
\hline & OLS & FE & BE & Precision & Study & IV \\
\hline SE (publication & $0.881^{* * *}$ & $0.656^{* * *}$ & $1.111^{* * *}$ & $1.025^{* * *}$ & $0.888^{* * *}$ & $2.186^{* * *}$ \\
bias) & $(0.086)$ & $(0.201)$ & $(0.190)$ & $(0.115)$ & $(0.094)$ & $(0.413)$ \\
& {$[0.49 ; 1.21]$} & - & - & {$[0.59 ; 1.40]$} & {$[0.62 ; 1.22]$} & {$[1.20 ; 3.68]$} \\
Constant (mean & $0.492^{* * *}$ & $0.529^{* * *}$ & $0.499^{* * *}$ & $0.468^{* * *}$ & $0.544^{* * *}$ & $0.279^{* * *}$ \\
beyond bias) & $(0.028)$ & $(0.033)$ & $(0.048)$ & $(0.025)$ & $(0.039)$ & $(0.070)$ \\
& {$[0.38 ; 0.61]$} & - & - & {$[0.36 ; 0.61]$} & {$[0.44 ; 0.64]$} & {$[0.04 ; 0.47]$} \\
\hline Studies & 121 & 121 & 121 & 121 & 121 & 121 \\
Observations & 3,186 & 3,186 & 3,186 & 3,186 & 3,186 & 3,186 \\
\hline
\end{tabular}

Notes: The table presents the results of regression $\hat{\sigma}_{i j}=\sigma_{0}+\gamma S E\left(\hat{\sigma}_{i j}\right)+u_{i j} . \hat{\sigma}_{i j}$ and $S E\left(\hat{\sigma}_{i j}\right)$ are the $i$-th estimates of elasticity of substitution and their standard errors reported in the $j$-th study. The standard errors of the regression parameters are clustered at both the study and country level and shown in parentheses (the implementation of twoway clustering follows Cameron et al. 2011). OLS = ordinary least squares. $\mathrm{FE}=$ study-level fixed effects. $\mathrm{BE}=$ study-level between effects. Precision = the inverse of the reported estimate's standard error is used as the weight. Study $=$ the inverse of the number of estimates reported per study is used as the weight. IV $=$ the inverse of the square root of the number of observations employed by researchers is used as an instrument for the standard error. ${ }^{* * *},{ }^{* *}$, and ${ }^{*}$ denote statistical significance at the $1 \%, 5 \%$, and $10 \%$ level. Standard errors in parentheses. Whenever possible, in square brackets we also report $95 \%$ confidence intervals from wild bootstrap clustering; implementation follows Roodman (2019), and we use Rademacher weights with 9999 replications.

The first column of Table 1 reports a simple OLS regression. The second column adds study-level fixed effects in order to account for unobserved study-specific characteristics, but little changes. (Adding country dummies would also produce similar results.) The third column uses between-study variance instead of within-study variance, and the estimate of the corrected mean remains not much affected. Next, we apply two weighting schemes. First, precision becomes the weight, as suggested by Stanley \& Doucouliagos (2017), which adjusts for the heteroskedasticity in the regression. Similar weights are also used in physics for meta-analyses of particle mass estimates (Baker \& Jackson, 2013). The corrected mean elasticity becomes a bit smaller, but not far from 0.5. Second, we weight the data by the inverse of the number of observations reported in a study, so that each study has the same impact on the results. Again, the difference is small in comparison to other specifications. In the last column we report the results of an instrumental variable (IV) regression. IV presents a crucial robustness check because in primary studies estimates and standard errors are jointly determined by the 
Table 2: Nonlinear techniques corroborate publication bias

\begin{tabular}{lllll}
\hline & $\begin{array}{l}\text { Bom \& Rachinger } \\
(2019)\end{array}$ & $\begin{array}{l}\text { Furukawa } \\
(2019)\end{array}$ & $\begin{array}{l}\text { Andrews \& Kasy } \\
(2019)\end{array}$ & $\begin{array}{l}\text { Ioaninidis } \\
\text { et al. }(2017)\end{array}$ \\
\hline Mean beyond bias & 0.52 & 0.55 & 0.43 & 0.50 \\
& $(0.09)$ & $(0.21)$ & $(0.02)$ & $(0.06)$ \\
\hline
\end{tabular}

Notes: Standard errors in parentheses. The method developed by Bom \& Rachinger (2019) searches for a precision threshold above which publication bias is unlikely. Methods developed by Furukawa (2019) and Andrews \& Kasy (2019) are described in detail in Appendix A and Appendix B The method developed by Ioannidis et al. (2017) focuses on estimates with adequate power.

estimation technique. If some techniques produce systematically larger standard errors and point estimates, our finding of publication bias could be spurious. An intuitive instrument for the standard error is the inverse of the square root of the number of observations used in the primary study: the root is correlated with the standard error by definition but is unlikely to be much correlated with the use of a particular estimation technique. Using IV we obtain a larger estimate of publication bias and a smaller estimate of the mean elasticity corrected for publication bias, $0.32^{2}$

The simple tests based on the Lombard effect and presented in Table 1 are intuitive but can themselves be biased if publication selection does not form a linear function of the standard error. For example, it might be the case that estimates are automatically reported if they cross a particular precision threshold. This is the intuition behind the estimator due to Bom \& Rachinger (2019) presented in Table 2. Bom \& Rachinger (2019) show how to estimate this threshold for each literature and introduce an "endogenous kink" technique that extends the linear test based on the Lombard effect. Next, Furukawa (2019) provides a nonparametric method that is robust to various assumptions regarding the functional form of publication bias and the underlying distribution of true effects. Furukawa (2019) suggests using only a portion of the most precise estimates, the stem of the funnel plot, and determines this portion by minimizing the trade-off between variance (decreasing in the number of estimates included) and bias (increasing in the number of imprecise estimates included). The stem-based method is generally more conservative than those commonly used, producing wide confidence intervals; the details are available in Appendix A.

Another nonlinear method to correct for publication bias is advocated by Andrews \& Kasy (2019). They show how the conditional publication probability (the probability of publication as a function of a study's results) can be nonparametrically identified and then describe how publication bias can be corrected if the conditional publication probability is known. The underlying intuition involves jumps in publication probability at conventional p-value cut-offs. Using their method, we estimate that positive elasticities are six times more likely to be published than negative ones. We include more details on the approach and estimation in Appendix B. Finally, the remaining estimate in Table 2 arises using the approach championed by Ioannidis et al. (2017), who focus only on estimates with adequate statistical power. We conclude that both

\footnotetext{
${ }^{2}$ The result is consistent with some estimation techniques or aspects of data influencing the point estimates and standard errors in opposite directions. In the next section we explicitly control for 71 aspects of study design, including data and methodology, and our final estimate also equals 0.3 .
} 
linear and nonlinear techniques agree that 0.5 represents a robust estimate of the mean elasticity of substitution after correcting the literature for publication bias. Since the uncorrected mean equals 0.9 , the exaggeration due to publication bias is almost twofold, consistent with the rule of thumb suggested by Ioannidis et al. (2017). Therefore, when we give the same weight to all approaches used in primary studies, the empirical literature as a whole provides no support for the Cobb-Douglas production function. But perhaps poor data and misspecifications bias the mean estimate downwards. We investigate this issue in the next section.

\section{Heterogeneity}

In Section 2 and Section 3 we discussed several prominent aspects of study design that might systematically influence the reported estimates of the elasticity. But many additional study characteristics can certainly play a role, and we need to control for them. To assign a pattern to the apparent heterogeneity in the literature, we collect 71 variables that reflect the context in which researchers obtain their estimates. The variables capture the characteristics of the data, specification choice, econometric approach, definition of the production function, and publication characteristics. (Moreover, the effects of different ways of measuring capital and labor are examined in subsamples of the main dataset and presented in Appendix D.) The variables, grouped in these categories, are discussed below and listed in Table C1 in Appendix C together with their definitions and summary statistics.

\subsection{Variables}

Data characteristics A central distinguishing feature of the studies concerns the level of data aggregation. Almost half (45\%) of the studies employ country- or state-level data, which forms our reference category. We include a dummy variable equal to one if the study uses industrylevel data ( $43 \%$ of the estimates) and firm-level data (12\% of the estimates). We also include a dummy equal to one when the resulting estimate does not represent the whole economy, but is reported at a disaggregated level for various industries. Moreover, we add controls for potential cross-country differences: a dummy for the US, developed European countries, and developing countries, as the substitutability between capital and labor may differ with the level of economic development and across institutional settings. For instance, Duffy \& Papageorgiou (2000) suggest that capital and labor become less substitutable in poorer countries.

To account for potential small-sample bias, we control for the number of observations used in each study. We also include the midpoint of the data period to capture a potential positive trend in the elasticity over time, which could be due to economic development within a country, a changing composition of the inputs, or changes in their relative efficiency (Cantore et al. 2017). Regarding data frequency, $89 \%$ of the estimates employ annual data; we thus use annual data as the baseline category and include a dummy variable for the use of quarterly data. Moreover, we control for data dimension - whether time series, cross-sectional, or panel data are used. Most of the studies employ time series data (around 53\%), which we take as the reference category. 
The final subset of variables covering data characteristics describes the source of data. Many estimates are based on data from the same databases - the largest number of studies employ data from the US Annual Survey of Manufactures and Census of Manufacturers. The second largest group is the KLEM database by Jorgenson (2007), followed by the OECD's International Sectoral Database and Structural Analysis Database. We do not have a prior on how data sources should affect estimates, yet still prefer not to ignore this potential source of variation and include the corresponding dummies as control variables.

Specification Concerning the specification of the various studies described in Section 2, we distinguish between estimation via single first-order conditions (FOCs); systems of more than one FOC; systems of the production function plus FOCs; linear approximations of the production function; and nonlinear estimation of the production function. We also discriminate between the FOC for labor based on the wage rate, FOC for capital based on the rental rate of capital, FOC for the capital-labor ratio based on the ratio between the wage rate and the rental rate of capital, FOC for capital share, and FOC for labor share in income. In total, this gives us nine distinct categories for estimation specification. We choose the FOC for capital based on the rental rate as the reference category because it represents the most frequently used specification (35\%), though closely followed by the FOC for labor based on the wage rate (33\% of estimates). A special case of the FOC for capital is its inverse estimation, in which the resulting estimates are labeled user-cost elasticities; examples include Smith (2008) and Chirinko et al. (2011).

Figure 6: Estimation form matters for the reported elasticities

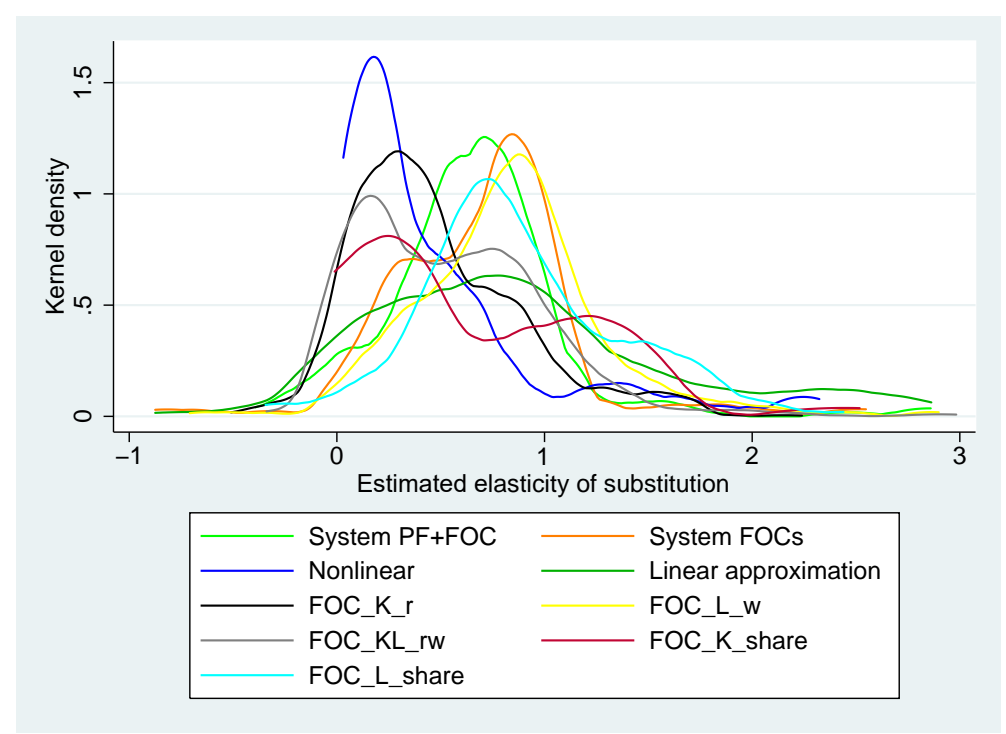

Notes: A detailed description of the variables is available in Table C1

The differences in estimates derived from the various specifications are clearly visible in the data (Figure 6). While the mean of the estimates derived from the FOC for labor based on the wage rate reaches 1.1, estimates derived from the FOC for capital based on the rental rate of capital are on average only 0.5. Estimates obtained from the linear approximation of the 
production function also stand out, reaching a mean value of 1.1. Some of these patterns were noted early in the history of the estimation of the elasticity, for example, by Berndt (1976), and later discussed by Antras (2004) and Young (2013). We attempt to quantify the patterns, while simultaneously controlling for other influences.

Regarding system estimations, two other important specification aspects can influence the reported elasticities: normalization and cross-equation restrictions. Normalization, suggested by de La Grandville (1989), further explored by Klump \& de La Grandville (2000), and first implemented empirically by Klump et al. (2007), has been used by only a small fraction of the studies in our database. Normalization starts from the observation that a family of CES functions whose members are distinguished only by different elasticities of substitution needs a common benchmark point. Since the elasticity of substitution is defined as a point elasticity, one needs to fix benchmark values for the level of production, factor inputs, and the marginal rate of substitution, or equivalently for per capita production, capital deepening, and factor income shares. Normalization essentially implies representing the production function in a consistent indexed number form. A proper choice of the point of normalization facilitates the identification of deep technical parameters. According to León-Ledesma et al. (2010), the superiority of the system estimation compared to the single FOC approach is further enhanced when complemented with normalization. In their Monte Carlo experiment they show that without normalization, estimates tend towards one.

Some estimations of systems employ cross-equation restrictions that restrict parameters across two or more equations to be equal, as in Zarembka (1970), Krusell et al. (2000), and Klump et al. (2007). To account for possible differences, we additionally include a dummy for cross-equation restrictions.

While the vast majority of estimates come from single-level production functions, estimates of the elasticity of substitution between capital and labor can also be found in studies using two-level production functions, including additional inputs such as energy and material, (e.g., Van der Werf, 2008; Dissou et al., 2015). We control for two-level production functions as a special case. Moreover, when estimates of the elasticity rely on such two-level production functions, linear approximations of the production function, or a system of a linear approximation in conjunction with share factors, researchers commonly report partial elasticities of substitution, for which we control as well. Our results are robust to excluding partial elasticities.

Econometric approach Our reference category for the choice of the econometric technique is OLS. We include a dummy for the case when the model is dynamic, which holds for approximately one-quarter of all observations. The second dummy we include equals one if seemingly unrelated regression (SUR) is used - often employed for the estimation of systems of equations (11\% of all estimates). An important aspect of estimating the elasticity, as pointed out by Chirinko (2008), is whether the estimate refers to a long-run or a short-run elasticity. Our reference category consists of explicit long-run specifications, that is, models in which coefficients are meant to be long-run and the specification is adjusted accordingly. We opt for long-run elasticities as a reference point as they are regarded as more informative for economic decisions. Ex- 
plicit long-run specifications include estimations of cointegration relations or interval-difference models, where data are averaged over longer intervals to mimic lower frequencies; distributed lag models can also give a long-run estimate. Conversely, the short-run approach modifies the estimating equation to account for temporal dynamics. Examples include estimation of implicit investment equations, as in Eisner \& Nadiri (1968) or Eisner (1969), differenced models, and estimation of short-run elements from error correction models or distributed lag models. The vast majority of estimates $(70 \%)$ are meant to be long-run but the specification is unadjusted.

Production function components The fourth category of control variables comprises the ingredients of the production function. We include a dummy variable for the case when other inputs (energy, materials, human capital) are considered as additional factors of production, for instance by Humphrey \& Moroney (1975), Bruno \& Sachs (1982), and Chirinko \& Mallick (2017). We include a dummy that equals one when a study differentiates between skilled and unskilled labor. We also subject the estimates to the following questions. Does the production function assume Hicks-neutral technological change (our reference category), Harrod-neutral technological change (i.e. labor-augmenting, LATC), or Solow-neutral technological change (i.e. capital-augmenting, CATC)? Are the dynamics of technological change important in explaining the heterogeneity? The growth rate of technological change can be either zero (our reference), constant or - with flexible Box \& Cox (1964) transformation - exponential, hyperbolic, or logarithmic. According to the impossibility theorem suggested by Diamond et al. (1978), it is infeasible to identify both the elasticity of substitution and the parameters of technological change at the same time, so researchers tend to impose one of the three specific forms of technological change and implicit or explicit assumptions on its growth rate. We include the corresponding dummy variables.

We distinguish between estimates of gross and net elasticity, based on whether gross or net data for output and the capital stock are used. As pointed out in Semieniuk (2017), the distinction between net and gross elasticity is important with respect to the inequality argument of Piketty (2014): for his explanation of the decline in the labor share to hold, $\sigma$ needs to exceed one in net terms. Elasticities based on net quantities should naturally yield smaller results (Rognlie, 2014). Finally, we include two additional dummies - first, for the case when researchers abandon the assumption of constant returns to scale; second, for the case when researchers relax the assumption of perfectly competitive markets.

Publication characteristics We include four study-level variables: the year of the appearance of the first draft of the paper in Google Scholar, a dummy for the paper being published in a top five journal, the recursive discounted RePEc impact factor of the outlet, and the number of citations per year since the first appearance of the paper in Google Scholar. We include these variables in order to capture aspects of study quality not reflected by observable differences in data and methods.

Moreover, we include two additional dummies. The first variable measures whether the study's central focus is the elasticity of substitution between capital and labor or whether the 
estimate is a byproduct of a different exercise, such as in Cummins \& Hassett (1992) and Chwelos et al. (2010). The second variable equals one if the author explicitly prefers the estimate in question, and equals minus one if the estimate is explicitly discounted. Nevertheless, researchers typically do not reveal their exact preferences regarding the individual estimates they produce, so the variable equals zero for most estimates.

\subsection{Estimation}

An obvious thing to do at this point is to regress the reported elasticities on the variables reflecting the context in which researchers obtain their estimates:

$$
\hat{\sigma}_{i j}=\alpha_{0}+\sum_{l=1}^{49} \beta_{l} X_{l, i j}+\gamma S E\left(\hat{\sigma}_{i j}\right)+\mu_{i j}
$$

where $\hat{\sigma}_{i j}$ again denotes estimate $i$ of the elasticity of substitution reported in study $j, X_{l, i j}$ represents control variables described in Subsection 5.1, $\gamma$ again denotes the intensity of publication bias, and $\alpha_{0}$ represents the mean elasticity corrected for publication bias but conditional on the definition of the variables included in $X$-that is, the intercept means nothing on its own, and $\mu_{i j}$ stands for the error term.

But using one regression is inadequate because of model uncertainty. With so many variables reflecting study design, including all of them would substantially attenuate the precision of our estimation. (We use 50 variables in the baseline estimation; the remaining 21 variables related to measurement of capital and labor and industry-level characteristics are included in the three subsamples presented in Appendix D.) One solution is to reduce the number of variables to about 10, which could allow for simple estimation - but doing so would ignore many aspects in which estimates and studies differ. Another commonly applied solution to model uncertainty is stepwise regression, but sequential t-tests are statistically problematic as individual variables can be excluded by accident. The solution that we choose here is Bayesian model averaging (BMA; see, for example, Eicher et al., 2011; Steel, 2019), which arises naturally as a response to model uncertainty in the Bayesian setting.

BMA runs many regression models with different subsets of variables; in our case there are $2^{50}$ possible subsets. Assigned to each model is a posterior model probability (PMP), an analog to information criteria in frequentist econometrics, measuring how well the model performs compared to other models. The resulting statistics are based on a weighted average of the results from all the regressions, the weights being the posterior model probabilities. For each variable we thus obtain a posterior inclusion probability (PIP), which denotes the sum of the posterior model probabilities of all the models in which the variable is included. Using the laptop on which we wrote this paper, it would take us decades to estimate all the possible models. So we opt for a model composition Markov Chain Monte Carlo algorithm (Madigan \& York, 1995) that walks through the models with the highest posterior model probabilities. In the baseline specification we use a uniform model prior (each model has the same prior probability) and unit 
information g-prior (the prior that all regression coefficients equal zero has the same weight as one observation in the data), but we also use alternative priors in Appendix D.

Second, as a simple robustness check of our baseline BMA specification, we run a hybrid frequentist-Bayesian model. We employ variable selection based on BMA (specifically, we only include the variables with PIPs above $80 \%$ ) and estimate the resulting model using OLS with clustered standard errors. We label this specification a "frequentist check" of the baseline BMA exercise. Third, we employ frequentist model averaging (FMA). Our implementation of FMA uses Mallows's criteria as weights since they prove asymptotically optimal (Hansen, 2007). The problem is that, using a frequentist approach, we have no straightforward alternative to the model composition Markov Chain Monte Carlo algorithm, and it appears infeasible to estimate all $2^{50}$ potential models. We therefore follow the approach suggested by Amini \& Parmeter (2012) and resort to orthogonalization of the covariate space.

\subsection{Results}

Figure 7 illustrates our results. The vertical axis depicts explanatory variables sorted by their posterior inclusion probabilities; the horizontal axis shows individual regression models sorted by their posterior model probabilities. The blue color indicates that the corresponding variable appears in the model and the estimated parameter has a positive sign, while the red color indicates that the estimated parameter is negative. In total, 21 variables appear to drive heterogeneity in the estimates, as their posterior inclusion probabilities surpass $80 \%$. Table 3 provides numerical results for BMA and the frequentist check. In the frequentist check we only include the 21 variables with PIPs above $80 \%$. Choosing a $50 \%$ threshold, for example, would result in including merely two more variables with virtually unchanged results for the remaining ones. Figure 8 plots posterior coefficient distributions of selected variables. The results of the FMA exercise are reported in Table D1 in Appendix D.

The first conclusion that we make based on these results is that our findings of publication bias presented in the previous section remain robust when we control for the context in which the elasticity is estimated. Indeed, the variable corresponding to publication bias, the standard error of the estimate, represents the single most effective variable in explaining the heterogeneity in the reported estimates of the elasticities of substitution (though several other variables also have posterior inclusion probabilities very close to $100 \%$ and are rounded to that number in Table 3). We observe that the publication bias detected by the correlation between estimates and standard errors is not driven by aspects of data and methods omitted from the univariate regression in Equation 13 .

Data characteristics Several characteristics related to the data used in primary studies systematically affect the estimates of the elasticity. Our results suggest a mild upward trend in the reported elasticities, which increase on average by 0.004 each year. (The yearly change does not equal the regression coefficient because the variable is in logs; the precise definition is available in Table C1.) The finding resonates with Cantore et al. (2017), who point to a similar 
Figure 7: Model inclusion in Bayesian model averaging

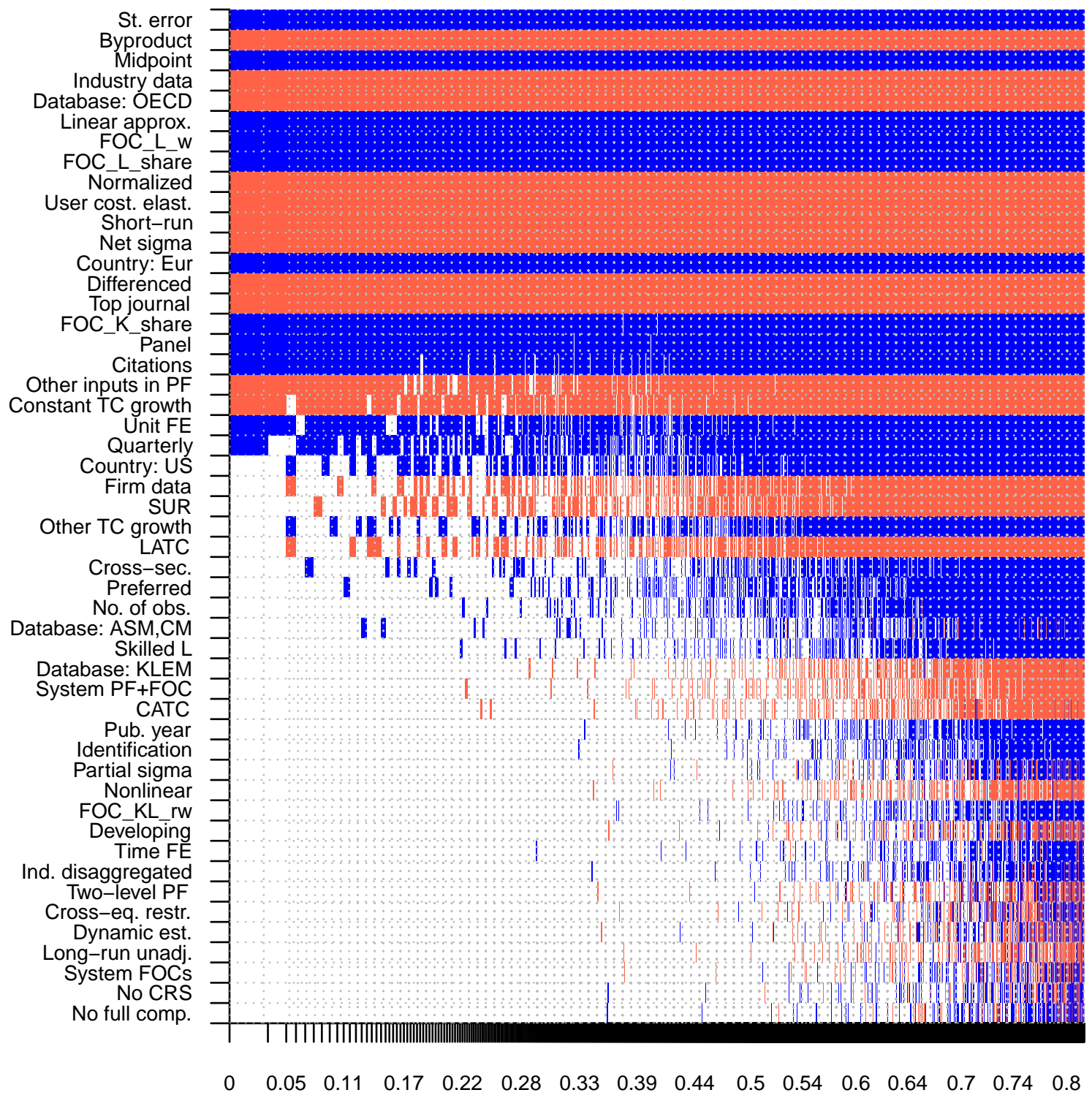

Notes: The response variable is the estimate of the elasticity of capital-labor substitution. Columns denote individual models; variables are sorted by posterior inclusion probability in descending order. FOC $=$ first-order condition. CATC = capital-augmenting technical change. LATC = labor-augmenting technical change. CRS = constant returns to scale. The horizontal axis denotes cumulative posterior model probabilities; only the 5,000 best models are shown. To ensure convergence we employ 100 million iterations and 50 million burn-ins. Blue color (darker in grayscale) = the variable is included and the estimated sign is positive. Red color (lighter in grayscale) = the variable is included and the estimated sign is negative. No color $=$ the variable is not included in the model. Numerical results of the BMA exercise are reported in Table 3 A detailed description of all variables is available in Table C1. 
Table 3: Why do estimates of the elasticity of substitution differ?

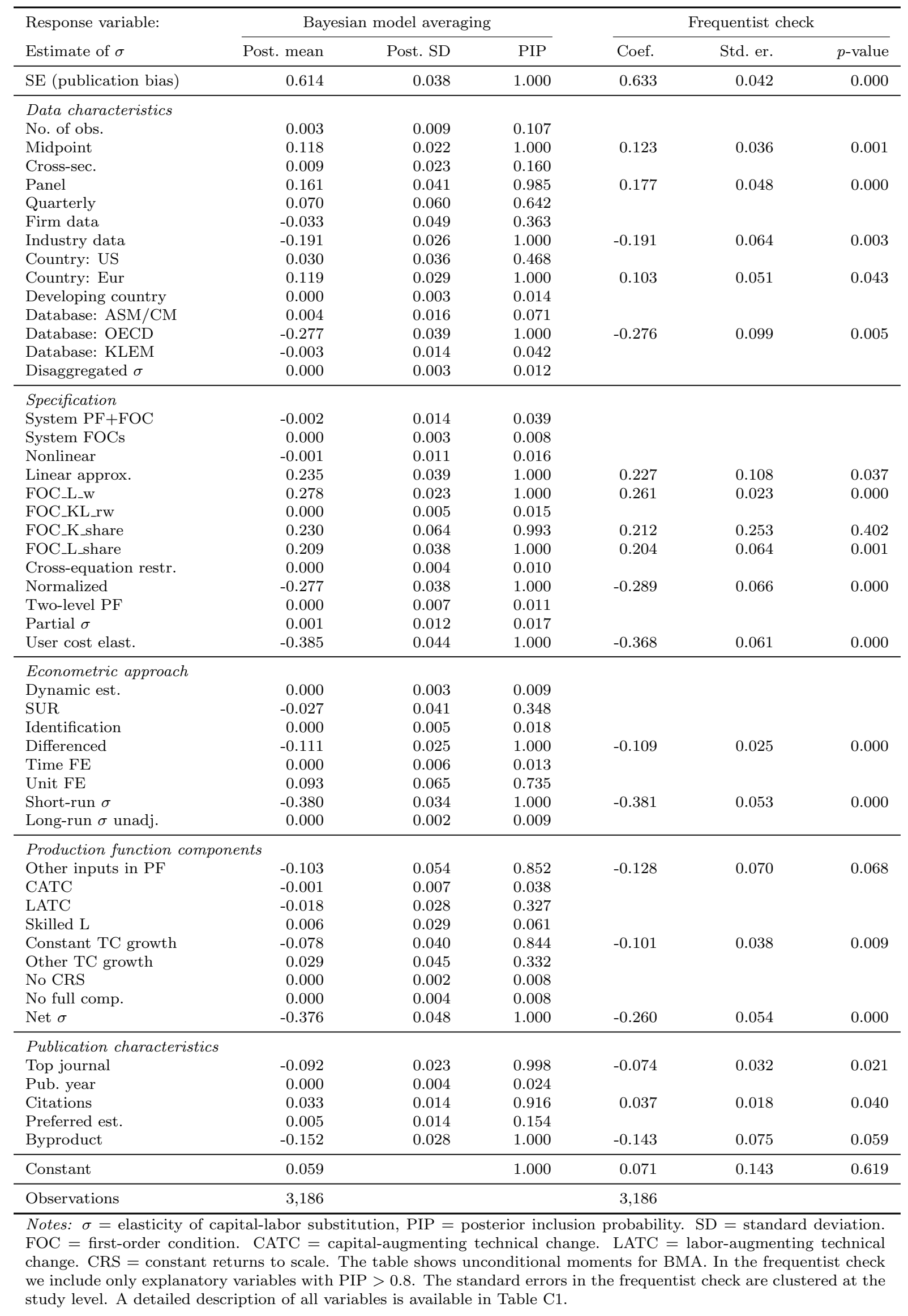


Figure 8: Posterior coefficient distributions for selected variables

Marginal Density: Industry data (PIP $100 \%$ )

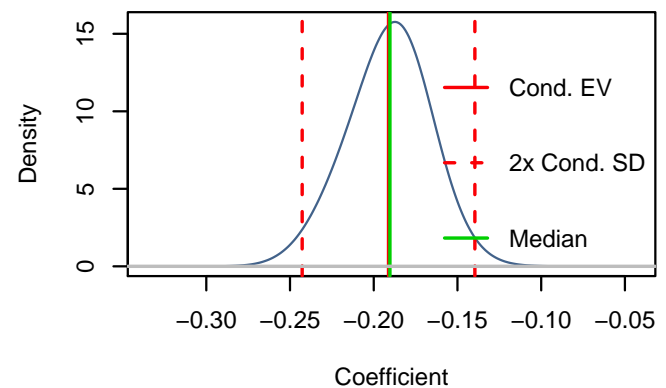

Marginal Density: Linear approx. (PIP $100 \%$ )

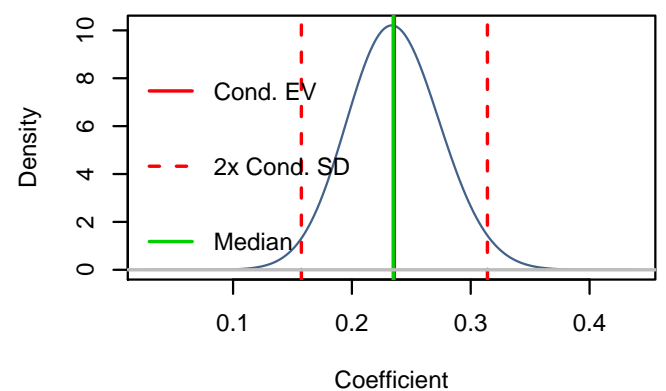

Marginal Density: Short-run (PIP $100 \%$ )

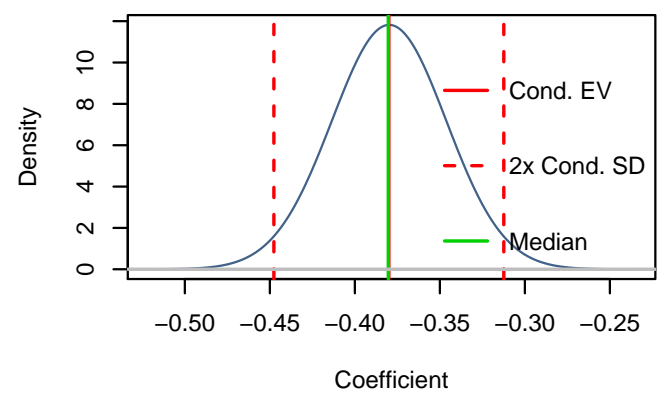

Marginal Density: FOC_L_w (PIP $100 \%$ )

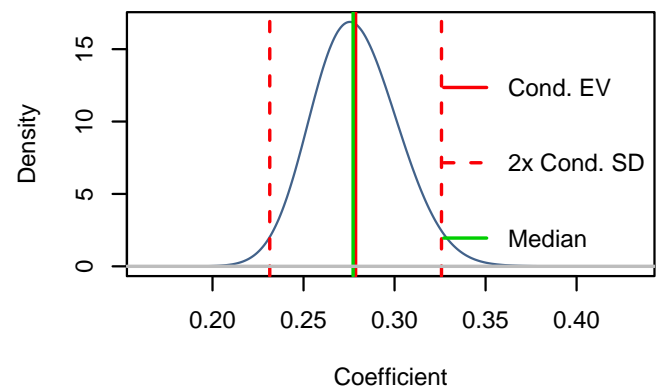

Marginal Density: Normalized (PIP $100 \%$ )

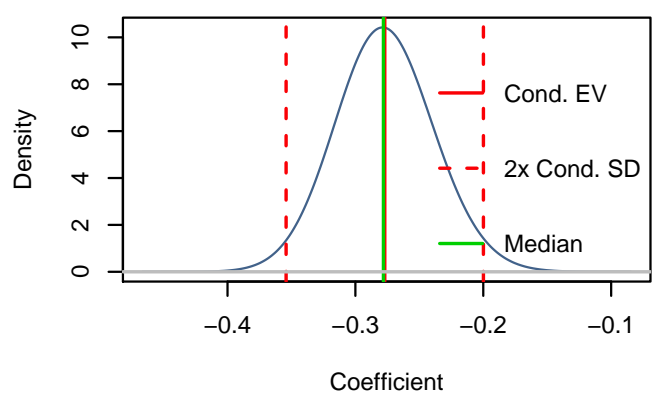

Marginal Density: Top journal (PIP $99.71 \%$ )

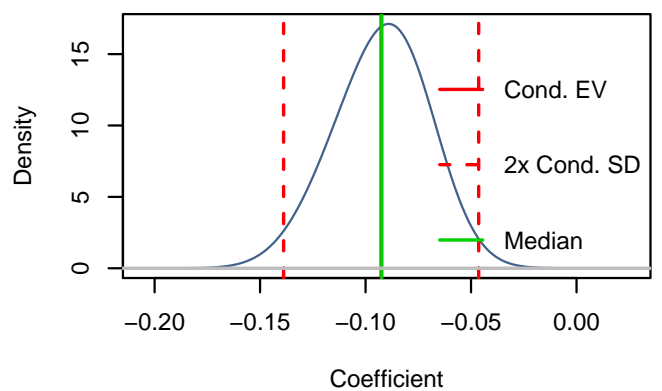

Notes: FOC_L_w $=1$ if the elasticity is estimated within the FOC for labor based on the wage rate. The figure depicts the densities of the regression parameters encountered in different regressions in which the corresponding variable is included (that is, the depicted mean and standard deviation are conditional moments, in contrast to those shown in Table 3. For example, the regression coefficient for Linear approximation is positive in all models, irrespective of specification. The most common value of the coefficient is 0.23 .

time trend. But the upward trend constitutes a poor reason to resurrect the Cobb-Douglas specification, because at this pace the specification will become consistent with the literature in about 175 years. Next, estimates of the elasticity that rely on industry-level data tend to be significantly smaller than those using country- or state-level data, a result corroborating the prima facie pattern in the literature shown in Figure 4(d) in Section 3. Nerlove (1967) suggests that using country-level data, implicitly assuming the same technological levels across countries, can lead to an upward bias in the estimated elasticity. Moreover, Chirinko (2008) discusses several 
drawbacks of aggregate data in comparison to firm- or industry-level data, including limited variation available for identification.

Concerning data dimension, our results suggest that panel data tend to yield larger estimates of the elasticity than time series data. The other prima facie pattern in the literature, the systematic and large difference between the results of time series and cross-section studies shown in Figure 4(c), breaks apart when controlling for other variables in BMA (the variable is statistically significant in FMA, but the estimated coefficient is small). Similarly, our results do not suggest that much of the differences between estimates can be explained by differences in data frequency.

Another prima facie data pattern, the importance of results aggregation presented in Figure 4(b), disappears in the BMA analysis. Elasticities computed for individual industries do not differ systematically from elasticities computed for the entire economy. Nevertheless, that is not to say that the elasticity does not vary across industries; we will return to this issue in Appendix D. Concerning cross-country differences, the reported elasticities tend to be larger in Europe than in other regions, but only by 0.1. Finally, our results suggest that datasets coming from the OECD database are associated with substantially smaller elasticities compared to all other data sources.

Specification A stylized fact in the literature on capital-labor substitution has it that estimations based on the first-order condition for labor deliver larger elasticities than estimations based on the first-order condition for capital; see Figure 4(a) in Section 3 . The BMA analysis corroborates this stylized fact and elaborates on it: when a system of FOCs is used, the results tend to be close to those derived from the FOC for capital. Omitting information from the FOC for capital, in contrast, exaggerates the reported elasticity by 0.2 or more. The FOC for capital thus seems to be more important for proper identification of the elasticity than the FOC for labor. The elasticity also becomes inflated by 0.2 when a linear approximation of the production function (using either the Kmenta or translog approach) is employed. As pointed out by Thursby \& Lovell (1978) and León-Ledesma et al. (2010), linear approximations of the production function tend to be biased towards $\hat{\sigma}=1$, as an elasticity of one usually serves as the initial point of expansion.

On the other hand, normalization of the production function systematically reduces the estimated elasticity by allowing for the identification of technological change parameters. Finally, if the FOC for capital is estimated in an inverse form (user cost elasticity of capital), the estimates tend to be on average much smaller. These results are robust across all the estimations we run: BMA, FMA, and the frequentist check. A similarly robust result is that the mean implied elasticity is 0.3 when made conditional on three aspects: (i) no publication bias, (ii) no country-level input data, and (iii) not ignoring information from the FOC for capital. We will expand and provide more details on the computation of the implied elasticity at the end of this section. 
Econometric approach We find little evidence that the econometric approach used in primary studies is responsible for systematic differences in the reported elasticities. Naturally, short-run elasticities are smaller than long-run ones: estimations in differences tend to deliver elasticities that are smaller by 0.1 ; explicitly short-run estimations tend to deliver elasticities smaller by 0.4. Adjusted and unadjusted long-run estimates do not differ much from each other.

Production function components The results suggest that assumptions regarding technical change have little systematic effect on the resulting elasticities of substitution. Allowing for capital- or labor-augmenting technological change brings, on average, elasticities similar to the case when Hicks-neutral technological change is assumed. Allowing for constant growth in technological change (in comparison to no growth) decreases the estimate, but only by a small margin. The apparent irrelevance of assumptions on technological change for the estimation of the elasticity of substitution contrasts with Antras (2004), who argues that Hicks-neutral technological change biases the results towards the Cobb-Douglas specification. The irrelevance finding holds for both BMA and FMA and regardless of whether we include labor- and capitalaugmenting technological change as separate dummies or jointly in one dummy.

Including other inputs in the production function aside from labor and capital has a negative effect on the resulting size of the elasticity. When the elasticity is estimated in the net form, it tends to be smaller by 0.4 on average, but very few studies pursue this approach.

Publication characteristics Out of the five variables grouped together as publication characteristics, three are systematically associated with the magnitude of the reported elasticity. First,

Figure 9: Posterior inclusion probabilities across different prior settings

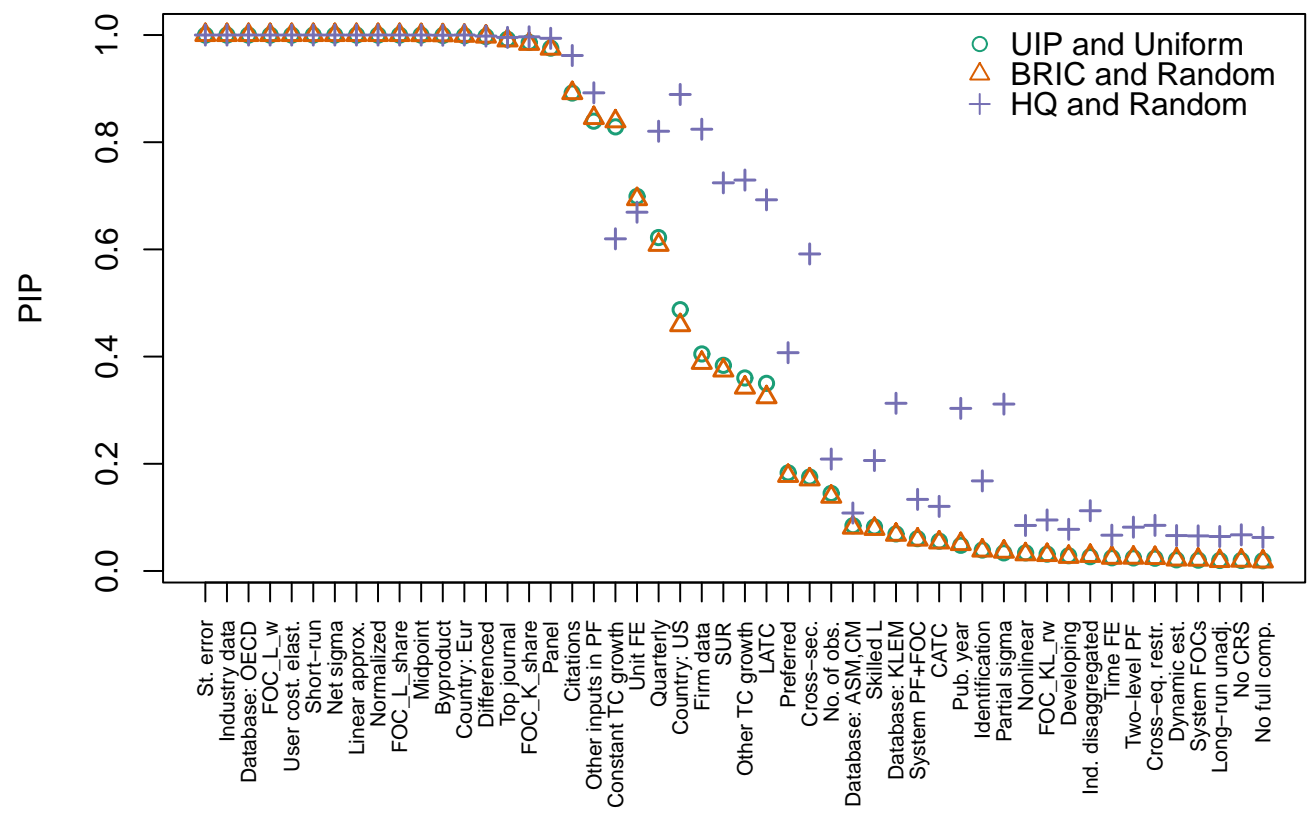

Notes: UIP (unit information prior) and Uniform model prior = priors according to Eicher et al. (2011). BRIC and Random = the benchmark g-prior for parameters with the beta-binomial model prior for the model space, which means that each model size has equal prior probability. HQ prior asymptotically mimics the Hannan-Quinn criterion. PIP = posterior inclusion probability. 
compared to other outlets, the top five journals in economics tend to publish slightly smaller elasticities. Second, studies that provide larger elasticities tend to receive more citationspotentially, such studies are more useful to researchers trying to justify the use of the CobbDouglas production function in their model, but it could also mean that studies reporting larger estimates are of higher quality. Third, the reported elasticity tends to be smaller if it does not represent the central focus of the study but merely a byproduct of a different exercise. One can interpret the finding as further indirect evidence of publication bias against small estimates, or, alternatively, as evidence that more thorough examinations yield larger estimates.

Aside from our baseline BMA, FMA, and frequentist check, we run several sensitivity analyses with respect to different subsamples of data, control variables, priors, and weighting schemes. Regarding priors, Figure 9 shows that the implied relative importance of the variables changes little when different priors are used for BMA. In Appendix D, we also run BMA on weighted data: first, data are weighted by the inverse of the number of estimates reported by each study so that each study has the same weight (Figure D1); second, data are weighted by the inverse of the standard error (Figure D2). Our key results continue to hold in these specifications.

\section{Economic significance and implied elasticity}

We close the analysis with a discussion of (i) the economic significance of the variables identified as important by BMA and FMA and (ii) the mean elasticity of substitution implied by the literature after taking into account the pattern that some data and method choices create in the reported estimates. Economic significance is explored in Table 4, which shows the effect on the reported elasticity when we increase the value of the corresponding variable by one standard deviation (the left-hand panel) and from minimum to maximum (the right-hand panel). Increasing from minimum to maximum perhaps makes more sense for dummy variables, while for continuous variables, such as the midpoint of data, the one-standard-deviation change is typically more informative. In the second and fourth column, the table also casts the effects as percentages of the "best-practice" estimate implied by the literature, which we discuss below. It is apparent from the table that the variables with the largest effect on the elasticity are the standard error (publication bias), industry-level data (disaggregation), FOC for labor (ignoring FOC for capital), normalization of the production function, and of course the assumption of short-run or net elasticity. Changes in these variables can easily alter the resulting elasticity by $50 \%$ or more.

The mean implied elasticity is explored in Table 5. In essence, we create a synthetic study in which we use all the reported estimates but give different weights to different aspects of data, methodology, and publication. We have already noted that the implied elasticity is 0.3 when we hold three preferences: the estimate should be conditional on the absence of publication bias, use of disaggregated (not country-level) data, and use of information from the first-order condition for capital. Next, we augment the list of preferences to construct a best-practice estimate. For the computation we use the results of FMA because, unlike BMA, it allows us to construct confidence intervals around the implied elasticities (linear combinations of FMA 
Table 4: Economic significance of key variables

\begin{tabular}{lrrrr}
\hline & \multicolumn{2}{c}{ One-std.-dev. change } & \multicolumn{2}{c}{ Maximum change } \\
& Effect on $\sigma$ & $\%$ of best practice & Effect on $\sigma$ & $\%$ of best practice \\
\hline Standard error & 0.117 & $39 \%$ & 0.461 & $154 \%$ \\
Byproduct & -0.047 & $-16 \%$ & -0.152 & $-51 \%$ \\
Midpoint & 0.056 & $19 \%$ & 0.588 & $196 \%$ \\
Industry data & -0.095 & $-32 \%$ & -0.191 & $-64 \%$ \\
Database: OECD & -0.069 & $-23 \%$ & -0.277 & $-92 \%$ \\
Linear approx. & 0.062 & $21 \%$ & 0.235 & $78 \%$ \\
FOC_L_w & 0.132 & $44 \%$ & 0.278 & $93 \%$ \\
Normalized & -0.061 & $-20 \%$ & -0.277 & $-92 \%$ \\
Short-run $\sigma$ & -0.083 & $-28 \%$ & -0.380 & $-127 \%$ \\
Net $\sigma$ & -0.059 & $-20 \%$ & -0.376 & $-125 \%$ \\
\hline
\end{tabular}

Notes: The table shows ceteris paribus changes in the reported elasticities implied by changes in the variables that reflect the context in which researchers obtain their estimates. For example, increasing the estimate's standard error by one standard deviation is associated with an increase in the estimated elasticity by 0.117 , more than a third of the size of the best practice estimate (one conditional on ideal data, method, and publication characteristics, as described in Table 5). Increasing the standard error from the sample minimum to the sample maximum is associated with an increase in the estimated elasticity by 0.461 , more than one and a half of the best practice estimate. A detailed description of the variables is available in Table C1 in Appendix C

coefficients and the chosen values for each variable). We compute fitted values of the elasticity by plugging in sample maxima for variables reflecting best practice in the literature, sample minima for variables reflecting departures from best practice, and sample means for variables where we cannot determine best practice.

Table 5: Results from a synthetic study

\begin{tabular}{|c|c|c|}
\hline & Implied elasticity & $95 \%$ confidence interval \\
\hline Best practice & 0.30 & $(-0.01,0.60)$ \\
\hline Short-run & -0.11 & $(-0.38,0.15)$ \\
\hline Net $\sigma$ & -0.02 & $(-0.30,0.25)$ \\
\hline Country-level data & 0.50 & $(0.18,0.81)$ \\
\hline Quarterly data & 0.42 & $(0.08,0.76)$ \\
\hline Time series & 0.25 & $(-0.10,0.60)$ \\
\hline Cross-sections & 0.32 & $(0.07,0.56)$ \\
\hline System of FOCs & 0.35 & $(0.07,0.64)$ \\
\hline
\end{tabular}

Notes: The table shows mean estimates of the elasticity of substitution conditional on data, method, and publication characteristics. The exercise is akin to a synthetic study that uses all information reported in the literature but puts more weight on selected aspects of study design. The result in the first column is conditional on our definition of best practice (see the main text for details). The remaining rows change one aspect in the definition of best practice: for example the second row shows the result for short-run instead of long-run estimates.

We prefer large studies using newer data, so we plug in sample maxima for the number of observations and midpoint of data. We prefer a system of production function together with FOCs for both capital and labor, tied with normalization and cross-equation restrictions. We also prefer the use of factor-augmenting technological change and joint estimation of equations by Zellner's method instead of OLS. As for the publication characteristics, we prefer studies 
that are highly cited and published in top journals. In contrast, we do not prefer linear approximation, byproduct estimates, elasticities that are supposed to be long-run but are not properly adjusted, and partial elasticities: we plug in zero for these variables. We do not have any strong opinion on the various sources of data or data dimension (whether time series or cross-sectional studies should be used, what data frequency should be employed). Thus, next to the central "best practice" estimate we generate multiple estimates for these data and method choices. We also show implied elasticities for aggregated, country-level data, often used in the literature, and for short-run elasticity, net elasticity, and the use of a system of FOCs without a production function.

The results, shown in Table 5, illustrate the high degree of uncertainty that such an exercise entails: the $95 \%$ confidence intervals for all estimates are approximately 0.6 wide. Our central estimate is still 0.3 , which means that other aspects of best practice (on top of the three preferences made in the beginning) cancel each other out - even though now the estimate becomes barely statistically significantly different from zero at the $5 \%$ level. But even such a conservative estimation rejects the Cobb-Douglas specification in all cases. The implied short-run and net elasticities are close to zero. When one prefers quarterly data instead of showing equal treatment to estimates derived from data of different frequencies, the implied estimate increases to 0.4. A preference for time series data, cross-sectional data, or a system of FOCs without a production function would result in a smaller change in the elasticity. Even a preference for country-level data would only take the implied estimate to 0.5 , with the upper bound of the $95 \%$ confidence interval at 0.8 , making the result safely inconsistent with the Cobb-Douglas specification.

\section{Concluding Remarks}

The Cobb-Douglas production function contradicts the data. This is the result we obtain after analyzing 3,186 estimates of the capital-labor substitution elasticity reported in 121 published studies. When we give the same weight to all the different approaches used to identify the elasticity, we find that the value most representative of the literature is 0.5 , tightly estimated with the upper bound of the $95 \%$ confidence interval at 0.6 . The representative value corresponds to the mean reported elasticity corrected for publication bias, a phenomenon that has not been previously addressed in the vast literature on the elasticity of substitution. The representative estimate further shrinks to 0.3 when one imposes the restrictions that identification must come from industry-level instead of aggregated, country-level data and that information from the first-order condition for capital must be considered instead of ignored. The representative estimate stays at 0.3 when we control for 71 aspects of study design and select a best-practice value for each aspect (plugging in mean values where no reasonable choice can be made). Such bestpractice elasticity is imprecisely estimated, with the upper bound of the $95 \%$ confidence interval still at 0.6. Other researchers will have different opinions on what constitutes best practice. But no matter the preferences, after acknowledging publication bias, the Cobb-Douglas production function with the elasticity at 1 becomes indefensible in the light of empirical evidence. 
We are not the first to highlight the disconnect between the Cobb-Douglas specification commonly used in macroeconomic models and the empirical literature estimating the elasticity of substitution. Chirinko (2008) and Knoblach et al. (2019) provide useful surveys of portions of the literature, and both studies suggest that the Cobb-Douglas production function is not backed by the available evidence. We argue that after controlling for publication bias and model uncertainty the case against Cobb-Douglas strengthens to the point where one has to warn against the continued use of this convenient simplification. As we show in the Introduction, a structural model built to aid monetary policy is biased from the beginning if it uses an elasticity of one for capital-labor substitution. Computational convenience should yield to the stylized fact established by half a century of meticulous research: capital and labor are gross complements.

Three caveats to the precise value of our central estimate, 0.3, are in order. First, the elasticities that we collect are unlikely to be independent because they are frequently derived from the same or similar datasets. We partially address this problem by clustering standard errors at both the study and country level when controlling for publication bias and additionally compute wild bootstrap confidence intervals. Second, the value of 0.3 is a mean estimate and does not necessarily fit all situations and calibrations. While we do not find much evidence of systematic differences in the elasticity across countries and industries, in a companion project we are currently working on a more detailed examination of structural determinants of the elasticity. Third, we do our best to include all published studies estimating the elasticity of substitution, but still we might have missed some. Such an omission will not affect our results much as long as it remains random. We experimented with randomly omitting $50 \%$ of our data set, and the main findings continue to hold in such simulations.

\section{References}

Amini, S. M. \& C. F. Parmeter (2012): "Comparison of Model Averaging Techniques: Assessing Growth Determinants." Journal of Applied Econometrics 27(5): pp. $870-876$.

Andrews, I. \& M. KASY (2019): "Identification of and Correction for Publication Bias." Americal Economic Review 109(8): pp. 2766-2794.

Antras, P. (2004): "Is the US Aggregate Production Function Cobb-Douglas? New Estimates of the Elasticity of Substitution." Contributions in Macroeconomics 4(1): pp. 1-36.

Arrow, K. J., H. B. Chenery, B. S. Minhas, \& R. M. Solow (1961): "Capital-Labor Substitution and Economic Efficiency." Review of Economics and Statistics 43(3): pp. 225-250.

Ashenfelter, O. \& M. Greenstone (2004): "Estimating the Value of a Statistical Life: The Importance of Omitted Variables and Publication Bias." American Economic Review 94(2): pp. 454-460.

BAKer, R. D. \& D. JACKson (2013): "Meta-Analysis Inside and Outside Particle Physics: Two Traditions that Should Converge?" Research Synthesis Methods
4(2): pp. 109-124.

Behrman, J. R. (1972): "Sectoral Elasticities of Substitution between Capital and Labor in a Developing Economy: Times Series Analysis in the Case of Postwar Chile." Econometrica 40(2): pp. 311-326.

BERndt, E. R. (1976): "Reconciling Alternative Estimates of the Elasticity of Substitution." Review of Economics and Statistics 58(1): pp. 59-68.

Bom, P. R. D. \& H. Rachinger (2019): "A Kinked Meta-Regression Model for Publication Bias Correction." Research Synthesis Methods (forthcoming).

Box, G. E. \& D. R. Cox (1964): "An Analysis of Transformations." Journal of the Royal Statistical Society: Series B (Methodological) 26(2): pp. 211-243.

Brown, M. (1966): "A Measure of the Change in Relative Exploitation of Capital and Labor." Review of Economics and Statistics 48(2): pp. 182-192.

Bruno, M. \& J. SAchs (1982): "Input Price Shocks and the Slowdown in Economic Growth: The Case of UK Manufacturing." Review of Economic Studies 49(5): pp. 679-705.

Cameron, A. C., J. B. Gelbach, \& D. L. Miller (2008): "Bootstrap-Based Improvements for Inference with Clustered Errors." Review of Economics 
and Statistics 90(3): pp. 414-427.

Cameron, A. C., J. B. Gelbach, \& D. L. Miller (2011): "Robust Inference with Multiway Clustering." Journal of Business $\&$ Economic Statistics 29(2): pp. 238-249.

Cantore, C., F. Ferroni, \& M. A. Leon-Ledesma (2017): "The Dynamics of Hours Worked and Technology." Journal of Economic Dynamics and Control 82: pp. $67-82$.

Cantore, C., M. León-Ledesma, P. McAdam, \& A. Willman (2014): "Shocking Stuff: Technology, Hours, and Factor Substitution." Journal of the European Economic Association 12(1): pp. 108-128.

Cantore, C., P. Levine, J. Pearlman, \& B. Yang (2015): "CES Technology and Business Cycle Fluctuations." Journal of Economic Dynamics and Control 61: pp. 133-151.

Card, D. \& A. B. Krueger (1995): "Time-Series Minimum-Wage Studies: A Meta-Analysis." American Economic Review 85(2): pp. 238-243.

Chirinko, R. S. (2002): "Corporate Taxation, Capital Formation, and the Substitution Elasticity between Labor and Capital." National Tax Journal 55(2): pp. 339-355.

Chirinko, R. S. (2008): " $\sigma$ : The Long and Short of it." Journal of Macroeconomics 30(2): pp. 671-686.

Chirinko, R. S., S. M. Fazzari, \& A. P. Meyer (2011): "A New Approach to Estimating Production Function Parameters: The Elusive Capital-Labor Substitution Elasticity." Journal of Business \& Economic Statistics 29(4): pp. 587-594.

Chirinko, R. S. \& D. Mallick (2017): "The Substitution Elasticity, Factor Shares, and the LowFrequency Panel Model." American Economic Journal: Macroeconomics 9(4): pp. 225-53.

Chwelos, P., R. Ramirez, K. L. Kraemer, \& N. P. Melville (2010): "Does Technological Progress Alter the Nature of Information Technology as a Production Input? New Evidence and New Results." Information Systems Research 21(2): pp. 392-408.

Cummins, J. G. \& K. A. Hassett (1992): "The Effects of Taxation on Investment: New Evidence from Firm Level Panel Data." National Tax Journal 45(3): pp. 243-251.

DeLong, J. B. \& K. LAng (1992): "Are All Economic Hypotheses False?" Journal of Political Economy 100(6): pp. 1257-72.

Dhrymes, P. J. (1965): "Some Extensions and Tests for the CES Class of Production Functions." Review of Economics and Statistics 47(4): pp. 357-366.

Diamond, P., D. McFadden, \& M. Rodriguez (1978): "Measurement of the Elasticity of Factor Substitution and Bias of Technical Change." In M. Fuss \& D. MCFADDEn (editors), "Contributions to Economic Analysis," volume 2, pp. 125-147. Elsevier.

Dissou, Y., L. Karnizova, \& Q. Sun (2015): "Industry-Level Econometric Estimates of Energy-
Capital-Labor Substitution with a Nested CES Production Function." Atlantic Economic Journal 43(1): pp. 107-121.

Doucouliagos, C. \& T. D. Stanley (2013): "Are All Economic Facts Greatly Exaggerated? Theory Competition and Selectivity." Journal of Economic Surveys 27(2): pp. 316-339.

Duffy, J. \& C. Papageorgiou (2000): "A CrossCountry Empirical Investigation of the Aggregate Production Function Specification." Journal of Economic Growth 5(1): pp. 87-120.

Eicher, T. S., C. Papageorgiou, \& A. E. Raftery (2011): "Default Priors and Predictive Performance in Bayesian Model Averaging, with Application to Growth Determinants." Journal of Applied Econometrics 26(1): pp. 30-55.

EIsneR, R. (1969): "Tax Policy and Investment Behavior: Comment." American Economic Review 59(3): pp. 379-388.

EISNER, R. \& M. I. NADIRI (1968): "Investment Behavior and Neo-Classical Theory." Review of Economics and Statistics 50(3): pp. 369-382.

Erceg, C. J., L. Guerrieri, \& C. Gust (2008): "Trade Adjustment and the Composition of Trade." Journal of Economic Dynamics and Control 32(8): pp. 2622-2650.

Ferguson, C. E. (1965): "Time-Series Production Functions and Technological Progress in American Manufacturing Industry." Journal of Political Economy 73(2): pp. 135-147.

Furukawa, C. (2019): "Publication Bias under Aggregation Frictions: Theory, Evidence, and a New Correction Method." Unpublished paper, MIT.

Hall, R. E. \& D. W. Jorgenson (1967): "Tax Policy and Investment Behavior." American Economic Review 57(3): pp. 391-414.

Hansen, B. E. (2007): "Least Squares Model Averaging." Econometrica 75(4): pp. 1175-1189.

Hedges, L. V. (1992): "Modeling Publication Selection Effects in Meta-Analysis." Statistical Science 7(2): pp. 246-255.

Hicks, J. R. (1932): "Marginal Productivity and the Principle of Variation." Economica (35): pp. 79-88.

Humphrey, D. B. \& J. R. Moroney (1975): "Substitution among Capital, Labor, and Natural Resource Products in American Manufacturing." Journal of Political Economy 83(1): pp. 57-82.

IoAnnidis, J. P., T. D. Stanley, \& H. Doucouliagos (2017): "The Power of Bias in Economics Research." Economic Journal 127(605): pp. 236-265.

Jorgenson, D. W. (1963): "Capital Theory and Investment Behavior." American Economic Review 53(2): pp. 247-259.

Jorgenson, D. W. (2007): "35 Sector KLEM." Harvard Dataverse.

Karabarbounis, L. \& B. Neiman (2013): "The Global 
Decline of the Labor Share." Quarterly Journal of Economics 129(1): pp. 61-103.

Kilponen, J., S. Orjasniemi, A. Ripatti, \& F. Verona (2016): "The Aino 2.0 Model." Bank of Finland Research Discussion Paper 16, Bank of Finland.

Klump, R. \& O. DE LA Grandville (2000): "Economic Growth and the Elasticity of Substitution: Two Theorems and Some Suggestions." American Economic Review 90(1): pp. 282-291.

Klump, R., P. McAdam, \& A. Willman (2007): "Factor Substitution and Factor-Augmenting Technical Progress in the United States: A Normalized SupplySide System Approach." Review of Economics and Statistics 89(1): pp. 183-192.

Kmenta, J. (1967): "On Estimation of the CES Production Function." International Economic Review 8(2): pp. $180-189$.

Knoblach, M., M. Rossler, \& P. Zwerschke (2019): "The Elasticity of Substitution Between Capital and Labour in the US Economy: A Meta-Regression Analysis." Oxford Bulletin of Economic and Statistics (forthcoming).

Krusell, P., L. E. Ohanian, J.-V. Roos-Rull, \& G. L. Violante (2000): "Capital-Skill Complementarity and Inequality: A Macroeconomic Analysis." Econometrica 68(5): pp. 1029-1053.

DE La Grandville, O. (1989): "In Quest of the Slutsky Diamond." American Economic Review 79(3): pp. $468-481$.

León-Ledesma, M. A., P. McAdam, \& A. Willman (2010): "Identifying the Elasticity of Substitution with Biased Technical Change." American Economic Review 100(4): pp. 1330-57.

Lovell, C. K. (1973): "CES and VES Production Functions in a Cross-Section Context." Journal of Political Economy 81(3): pp. 705-720.

Madigan, D. \& J. YorK (1995): "Graphical Models for Discrete Data." International Statistical Review 63(2): pp. 215-232.

McCloskey, D. N. \& S. T. Ziliak (2019): "What Quantitative Methods Should We Teach to Graduate Students? A Comment on Swann's Is Precise Econometrics an Illusion?" Journal of Economic Eduation (forthcoming).

Nekarda, C. J. \& V. A. Ramey (2013): "The Cyclical Behavior of the Price-Cost Markup." NBER Working Paper 19099, National Bureau of Economic Research.

Nerlove, M. (1967): "Recent Empirical Studies of the CES and Related Production Functions." In M. Brown (editor), "The Theory and Empirical Analysis of Production," pp. 55-136. NBER.

Piketty, T. (2014): Capital in the 21st Century. Cambridge, MA: Harvard University Press.

Robinson, J. (1933): Economics of Imperfect Compe- tition. New York: The Macmillan Company.

Rognlie, M. (2014): "A Note on Piketty and Diminishing Returns to Capital." Unpublished paper, MIT.

Roodman, D. (2019): "BOOTTEST: Stata Module to Provide Fast Execution of the Wild Bootstrap with Null Imposed." Statistical Software Components from Boston College Department of Economics.

Rusnak, M., T. Havranek, \& R. Horvath (2013): "How to Solve the Price Puzzle? A Meta-Analysis." Journal of Money, Credit and Banking 45(1): pp. $37-70$.

Semieniuk, G. (2017): "Piketty's Elasticity of Substitution: A Critique." Review of Political Economy 29(1): pp. 64-79.

Smith, J. (2008): "That Elusive Elasticity and the Ubiquitous Bias: Is Panel Data a Panacea?" Journal of Macroeconomics 30(2): pp. 760-779.

Solow, R. M. (1956): "A Contribution to the Theory of Economic Growth." Quarterly Journal of Economics 70(1): pp. 65-94.

Stanley, T., S. B. Jarrell, \& H. Doucouliagos (2010): "Could it Be Better to Discard 90\% of the Data? A Statistical Paradox." American Statistician 64(1): pp. 70-77.

Stanley, T. D. (2005): "Beyond Publication Bias." Journal of Economic Surveys 19(3): pp. 309-345.

Stanley, T. D. \& H. Doucouliagos (2010): "Picture This: A Simple Graph that Reveals Much Ado about Research." Journal of Economic Surveys 24(1): pp. 170-191.

Stanley, T. D. \& H. Doucouliagos (2017): "Neither Fixed nor Random: Weighted Least Squares MetaRegression." Research Synthesis Methods 8(1): pp. 19-42.

Steel, M. F. J. (2019): "Model Averaging and its Use in Economics." Journal of Economic Literature (forthcoming).

Thursby, J. G. \& C. K. Lovell (1978): "An Investigation of the Kmenta Approximation to the CES Function." International Economic Review 19(2): pp. 363-377.

Turnovsky, S. J. (2002): "Intertemporal and Intratemporal Substitution, and the Speed of Convergence in the Neoclassical Growth Model." Journal of Economic Dynamics and Control 26(9-10): pp. 1765-1785.

VAN DER WeRF, E. (2008): "Production Functions for Climate Policy Modeling: An Empirical Analysis." Energy Economics 30(6): pp. 2964-2979.

YounG, A. T. (2013): "US Elasticities of Substitution and Factor Augmentation at the Industry Level." Macroeconomic Dynamics 17(4): pp. 861-897.

ZarembKa, P. (1970): "On the Empirical Relevance of the CES Production Function." Review of Economics and Statistics 52(1): pp. 47-53. 


\section{Appendix A Furukawa's Method for Addressing Selective Re- porting (for Online Publication)}

Appendices $A, B, C, D$, and $E$ are only presented here for the convenience of reviewers. If the manuscript is accepted for publication, this material will be relegated to an online appendix.

Furukawa (2019) proposes the so-called stem-based correction method, which relies on the most precise studies, corresponding to the stem of the funnel plot. The method is nonparametric, fully data-dependent and requires weaker assumptions for the underlying distribution of true effects and the publication selection process than other methods. Publication selection can be a function of the size of the estimates, their significance, or both at the same time, as imprecise null results are less likely to be published. By focusing on the $n$ most precise estimates, Furukawa (2019) is able to account for various publication selection processes. The method extends the approach by Stanley et al. (2010), who suggest using 10\% of the most precise estimates. Instead of selecting an arbitrary number of the most precise estimates, Furukawa (2019) suggests a formal method to calculate the optimal number $n$ of the most precise studies to include by minimizing the mean squared error:

$$
\min _{n} M S E(n)=\operatorname{Bias}^{2}(n)+\operatorname{Var}(n) .
$$

With more studies used, the squared bias term increases as less precise studies suffer from more bias, but the variance term decreases as more information increases efficiency. An empirical analog of the bias term is estimated nonparametrically using two algorithms. The inner algorithm computes the bias-corrected mean given an assumed value of squared precision, and the outer algorithm computes the implied variance and ensures that it is consistent with its assumed value. The inner algorithm ranks and indexes studies in an ascending order according to their standard error, se, and for each $n=2, \ldots, N$ calculates the relevant bias squared and variance, given the assumed value of $s e_{0}$ :

$$
\begin{gathered}
\operatorname{Bias}^{2}(n)=\frac{\sum_{i=2}^{n} \sum_{j \neq i}^{n} w_{i} w_{j} \beta_{i} \beta_{j}}{\sum_{i=2}^{n} \sum_{j \neq i}^{n} w_{i} w_{j}}-2 \beta_{1} \frac{\sum_{i=2}^{n} w_{i} \beta_{i}}{\sum_{i=2}^{n} w_{i}}, \\
\operatorname{Var}(n)=\sum_{i=1}^{n} w_{i},
\end{gathered}
$$

where $w_{i}=\frac{1}{s e_{i}^{2}+s e_{0}^{2}}$. The optimal number of included studies is given by Equation 15. The stem-based corrected estimate follows:

$$
\hat{b}_{\text {stem }}=\frac{\sum_{i=1}^{n_{\text {stem }}} w_{i} \beta_{i}}{\sum_{i=1}^{n_{\text {stem }}} w_{i}}
$$

The outer algorithm then searches over $s e_{0}^{2}$ so that the implied variance is consistent.

The stem-based method applied to the elasticity of substitution yields the following results: the mean underlying elasticity corrected for publication bias is 0.57 with a standard error of 
0.05. Overall, $77 \%$ of the total information in the data is utilized, and the 83 most precise studies (out of 121) are included. Because the stem-based method uses study-level estimates (as preferred by Furukawa), we select median values from each study. Figure A1 visualizes the stem-based bias correction method. Figure A2 visualizes the bias-variance trade-off in order to minimize the mean squared error. When all estimates instead of median estimates are used, the mean corrected elasticity is similar, 0.55 , but the standard error increases to 0.21 .

Figure A1: A graphical illustration of Furukawa's technique

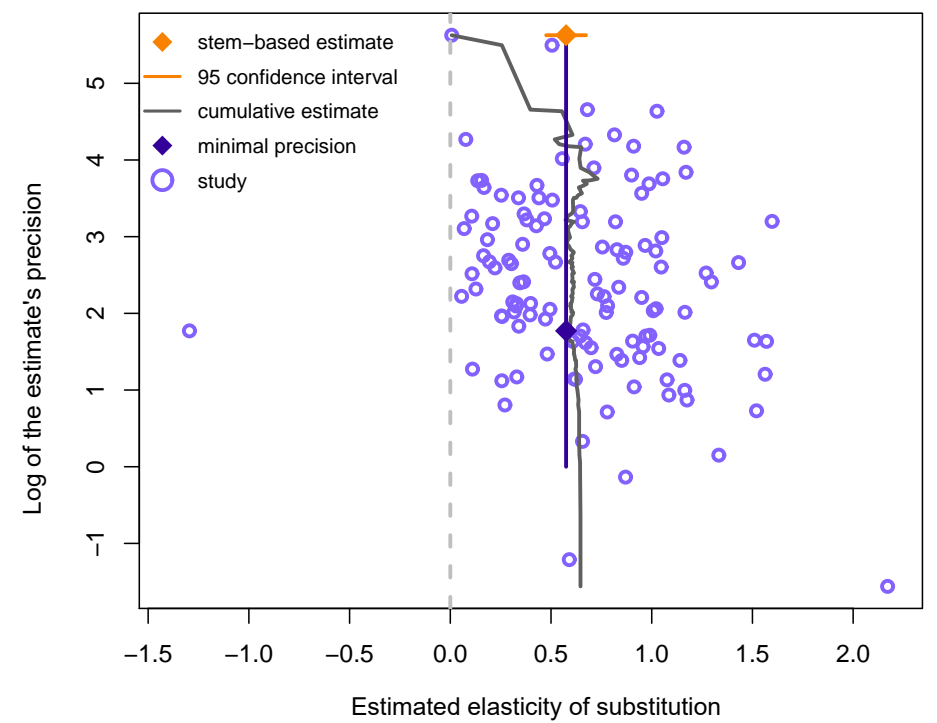

Note: The orange (lighter in grayscale) diamond at the top corresponds to the stem-based estimate of the mean elasticity corrected for publication bias, with the orange line indicating the corresponding $95 \%$ confidence interval. The gray (lighter in grayscale) line denotes the estimate under various $n_{\text {stem }} \in 1, \ldots, N$. The blue (darker in grayscale) diamond indicates the minimum precision level that defines the "stem" of the funnel.

Figure A2: The trade-off between bias and variance
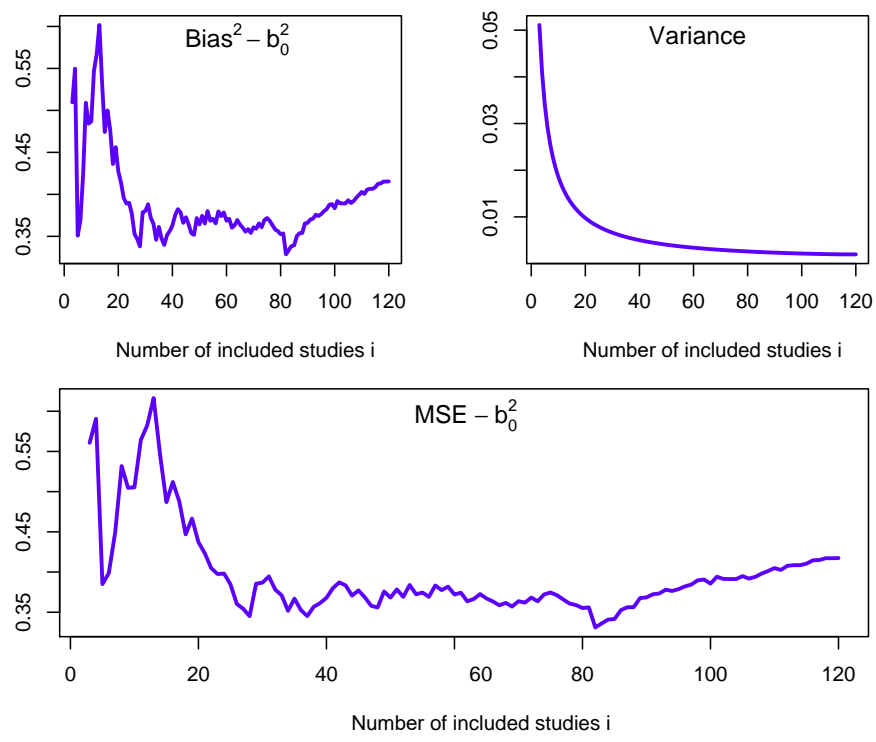

Note: The mean squared error (MSE) is the criterion for choosing the $n_{\text {stem }}$, the optimal number of studies to include in the stem-based estimator. The relevant components of MSE-bias and variance - are plotted. 


\section{Appendix B Andrews and Kasy's Method for Addressing Se- lective Reporting (for Online Publication)}

Andrews \& Kasy (2019) introduce two approaches for the identification of publication selection: the first one based on data from replication studies and the second one tailored for meta-analysis. They show that the meta-analysis approach delivers results similar to the approach based on replications. In the absence of publication bias, the distribution of the estimates from imprecise studies can be written as the distribution for precise studies plus noise; deviations from this form identify conditional publication probabilities. Andrews \& Kasy (2019) identify publication probability similarly to Hedges (1992) using maximum likelihood: conditional publication probability, $p(\cdot)$, is a step function with jumps at conventional critical values of the p-value.

When applied to our data, the method by Andrews \& Kasy (2019) yields the following results. The bias-corrected estimate is 0.43 with a standard error of 0.017 . We impose a cutoff at zero, that is, we compare the publication probability of negative vs. positive estimates regardless of their significance. (Allowing for other jumps in publication probability would yield even smaller estimates of the mean elasticity corrected for publication bias.) Our results also suggest that positive estimates are six times more likely to be selected for publication than negative estimates (Table B1). In the case of the elasticity of substitution, publication selection based on statistical significance is apparently less pronounced than selection based on the sign of the estimate, as suggested by the right panel of Figure B1.

Figure B1: A graphical illustration of Andrews and Kasy's (2019) estimator
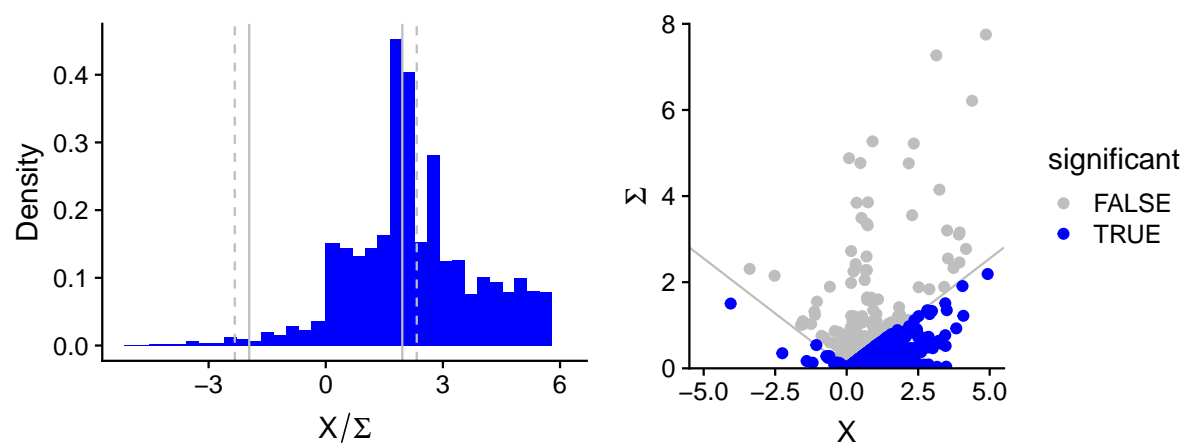

Note: The solid gray lines mark $t$-statistic equal to 1.96 in absolute value; the dashed gray line marks $t$-statistics equal to 2.33 in absolute value. We observe a jump at $t$-statistic equal to zero and then also jumps at conventional significance levels. The right-hand figure plots estimates $\mathrm{X}$ and their standard errors $\Sigma$; the gray line marks 1.96 in absolute value. Even though we observe discontinuity at the $t$-statistic corresponding to the $5 \%$ significance level, the right panels shows publication selection based on significance is not absolute, as some insignificant estimates (gray points) are reported.

Table B1: Results of Andrews and Kasy's (2019) estimator

\begin{tabular}{lllll}
\hline & $\bar{\theta}$ & $\bar{\tau}$ & DF & $\beta_{p}$ \\
\hline Estimate & 0.430 & 0.489 & 12.809 & 0.158 \\
Standard error & 0.017 & 0.012 & 0.707 & 0.019 \\
\hline
\end{tabular}

Notes: $\bar{\theta}$ denotes the bias-corrected mean effect, $\bar{\tau}$ is a scale parameter, $D F$ are degrees of freedom. $\beta_{p}$ is a publication probability measured relative to the omitted category, in our case positive estimates. An estimate of 0.158 therefore implies that negative results are $15.8 \%$ as likely to be published as positive ones. 


\section{Appendix C Description of Variables (for Online Publication)}

Table C1: Definitions and summary statistics of explanatory variables

\begin{tabular}{|c|c|c|c|}
\hline Variable & Description & Mean & Std. dev. \\
\hline \multicolumn{4}{|l|}{ Data characteristics } \\
\hline No. of obs. & $\begin{array}{l}\text { The logarithm of the number of observations used in the re- } \\
\text { gression. }\end{array}$ & 4.28 & 1.51 \\
\hline Midpoint & $\begin{array}{l}\text { The logarithm of the mean year of the data used minus the } \\
\text { earliest mean year in our data. }\end{array}$ & 4.71 & 0.48 \\
\hline Cross-sec. & $\begin{array}{l}=1 \text { if cross-sectional data are used (reference category: time } \\
\text { series). }\end{array}$ & 0.33 & 0.47 \\
\hline Panel & $=1$ if panel data are used (reference category: time series). & 0.14 & 0.35 \\
\hline Quarterly & $\begin{array}{l}=1 \text { if the data frequency is quarterly (reference category: an- } \\
\text { nual). }\end{array}$ & 0.11 & 0.31 \\
\hline Industry data & $\begin{array}{l}=1 \text { if industry-/sector-level data are used as input data (ref- } \\
\text { erence category: country-/state-level data). }\end{array}$ & 0.43 & 0.50 \\
\hline Firm data & $\begin{array}{l}=1 \text { if firm-level data are used as input data (reference cate- } \\
\text { gory: country-/state-level data). }\end{array}$ & 0.12 & 0.32 \\
\hline Country: US & $=1$ if the estimate is for the US. & 0.58 & 0.49 \\
\hline Country: Eur & $=1$ if the estimate is for a developed European country. & 0.17 & 0.37 \\
\hline Developing & $\begin{array}{l}=2 \text { if the estimate is for a developing country; }=1 \text { if the } \\
\text { estimate is a common estimate for a collection of developed } \\
\text { and developing countries (reference category: developed coun- } \\
\text { tries). }\end{array}$ & 0.22 & 0.54 \\
\hline Database: OECD & $=1$ if the data come from the OECD database. & 0.07 & 0.25 \\
\hline Database: KLEM & $=1$ if the data come from the Jorgenson KLEM dataset. & 0.15 & 0.36 \\
\hline Database: ASMCM & $\begin{array}{l}=1 \text { if the data come from the Annual Survey of Manufacturers } \\
\text { and/or Census of Manufacturers. }\end{array}$ & 0.14 & 0.35 \\
\hline Disaggregated $\sigma$ & $\begin{array}{l}=1 \text { if the elasticity is estimated on a disaggregated level } \\
\text { (industry-specific elasticity). }\end{array}$ & 0.52 & 0.50 \\
\hline \multicolumn{4}{|l|}{ Specification } \\
\hline System PF-FOC & $\begin{array}{l}=1 \text { if the elasticity is estimated within a system of CES with } \\
\text { FOC(s) or with cost share functions. }\end{array}$ & 0.06 & 0.23 \\
\hline System FOCs & $=1$ if the elasticity is estimated within a system of FOCs. & 0.05 & 0.23 \\
\hline Nonlinear & $\begin{array}{l}=1 \text { if the elasticity is estimated within the CES directly via } \\
\text { nonlinear methods. }\end{array}$ & 0.04 & 0.20 \\
\hline Linear approx. & $\begin{array}{l}=1 \text { if the elasticity is estimated via Taylor series expansion } \\
\text { (Kmenta approach or translog approach). }\end{array}$ & 0.07 & 0.26 \\
\hline FOC_L_w & $\begin{array}{l}=1 \text { if the elasticity is estimated within the FOC for labor } \\
\text { based on the wage rate (reference category: FOC for capital } \\
\text { based on the rental rate of capital). }\end{array}$ & 0.33 & 0.47 \\
\hline FOC_KL_rw & $\begin{array}{l}=1 \text { if the elasticity is estimated within the } \mathrm{FOC} \text { of } \mathrm{K} / \mathrm{L} \text { based } \\
\text { on } \mathrm{w} / \mathrm{r} \text { (reference category: FOC for capital based on the } \\
\text { rental rate of capital). }\end{array}$ & 0.18 & 0.39 \\
\hline FOC_K_share & $\begin{array}{l}=1 \text { if the elasticity is estimated within the FOC for capital } \\
\text { based on the capital share (reference category: FOC for capital } \\
\text { based on the rental rate of capital). }\end{array}$ & 0.03 & 0.16 \\
\hline FOC_L_share & $\begin{array}{l}=1 \text { if the elasticity is estimated within the FOC for labor } \\
\text { based on the labor share (reference category: FOC for capital } \\
\text { based on the rental rate of capital). }\end{array}$ & 0.04 & 0.19 \\
\hline User cost elast. & $=1$ if the user cost of capital elasticity is estimated. & 0.17 & 0.38 \\
\hline Cross-equation rest. & $\begin{array}{l}=1 \text { if cross-equation restrictions are employed when using sys- } \\
\text { tem estimation. }\end{array}$ & 0.08 & 0.28 \\
\hline Normalized & $=1$ if normalization is applied to the CES. & 0.05 & 0.22 \\
\hline
\end{tabular}


Table C1: Definitions and summary statistics of explanatory variables (continued)

\begin{tabular}{|c|c|c|c|}
\hline Variable & Description & Mean & Std. dev. \\
\hline Two-level PF & $\begin{array}{l}=1 \text { if a two-level CES function is estimated (due to more than } \\
\text { two factors of production). }\end{array}$ & 0.03 & 0.18 \\
\hline Partial $\sigma$ & $\begin{array}{l}=1 \text { if some form of partial elasticity is used (Allen-Uzawa, } \\
\text { Hicks-Allen, Morishima). }\end{array}$ & 0.06 & 0.24 \\
\hline \multicolumn{4}{|l|}{ Econometric approach } \\
\hline Dynamic est. & $\begin{array}{l}=1 \text { if dynamic methods are used for estimation (VAR, a dis- } \\
\text { tributed lag model or error correction model; reference cate- } \\
\text { gory: OLS). }\end{array}$ & 0.24 & 0.42 \\
\hline SUR & $\begin{array}{l}=1 \text { if a system of seemingly unrelated regressions is used (Zell- } \\
\text { ner's estimation; reference category: OLS). }\end{array}$ & 0.11 & 0.31 \\
\hline Differenced & $\begin{array}{l}=1 \text { if the coefficient is taken from a regression in first differ- } \\
\text { ences or log differences. }\end{array}$ & 0.23 & 0.42 \\
\hline Time FE & $=1$ if time-fixed effects are used for estimation. & 0.06 & 0.24 \\
\hline Unit FE & $=1$ if unit-fixed effects are used for estimation. & 0.04 & 0.20 \\
\hline Identification & $=1$ if instrumental variables are used for identification. & 0.13 & 0.34 \\
\hline Short-run $\sigma$ & $\begin{array}{l}=1 \text { if the coefficient is taken from an explicit short-run spec- } \\
\text { ification (reference category: explicit long-run specification- } \\
\text { cointegration, low-pass filter, interval-difference model). }\end{array}$ & 0.05 & 0.22 \\
\hline Long-run $\sigma$ unadj. & $\begin{array}{l}=1 \text { if the coefficient is meant to be long-run but the specifica- } \\
\text { tion is not adjusted accordingly (reference category: explicit } \\
\text { long-run specification). }\end{array}$ & 0.68 & 0.47 \\
\hline \multicolumn{4}{|c|}{ Production function components } \\
\hline Other inputs in $\mathrm{PF}$ & $\begin{array}{l}=1 \text { if the production function includes other inputs such as } \\
\text { energy, materials, and human capital. }\end{array}$ & 0.13 & 0.34 \\
\hline LATC & $\begin{array}{l}=1 \text { if the production function includes labor-augmenting tech- } \\
\text { nological change, i.e. Harrod-neutral technological change } \\
\text { (reference category: Hicks-neutral technological change). }\end{array}$ & 0.29 & 0.63 \\
\hline CATC & $\begin{array}{l}=1 \text { if the production function includes capital-augmenting } \\
\text { technological change, i.e. Solow-neutral technological change } \\
\text { (reference category: Hicks-neutral technological change). }\end{array}$ & 0.26 & 0.57 \\
\hline Skilled L & $\begin{array}{l}=1 \text { if the production function distinguishes between skilled } \\
\text { and unskilled labor. }\end{array}$ & 0.02 & 0.13 \\
\hline $\begin{array}{l}\text { Constant } \\
\text { growth }\end{array}$ & $\begin{array}{l}=1 \text { if the technological change is modeled with constant } \\
\text { growth rates (reference category: no growth of technology). }\end{array}$ & 0.30 & 0.46 \\
\hline Other TC growth & $\begin{array}{l}=1 \text { if the technological change is modeled with nonconstant } \\
\text { growth rates, e.g., logarithmic, linear (reference category: no } \\
\text { growth of technology). }\end{array}$ & 0.10 & 0.31 \\
\hline No CRS & $=1$ if the authors assume nonconstant returns to scale. & 0.09 & 0.36 \\
\hline No full comp. & $\begin{array}{l}=1 \text { if the authors do not assume factor markets to be perfectly } \\
\text { competitive. }\end{array}$ & 0.04 & 0.19 \\
\hline Net $\sigma$ & $\begin{array}{l}=1 \text { if net elasticity is estimated (reference category: gross } \\
\text { elasticity). }\end{array}$ & 0.02 & 0.16 \\
\hline \multicolumn{4}{|l|}{ External info } \\
\hline Top journal & $=1$ if the study is published in a top five journal in economics. & 0.31 & 0.46 \\
\hline Pub. year & $\begin{array}{l}\text { The logarithm of the year when the first draft of the study } \\
\text { appeared in Google Scholar minus the year when the first study } \\
\text { on elasticity of substitution was written. }\end{array}$ & 3.25 & 0.88 \\
\hline Impact & The recursive discounted RePEc impact factor of the outlet. & 0.96 & 1.07 \\
\hline Citations & $\begin{array}{l}\text { The logarithm of the number of per-year citations of the study } \\
\text { since its first appearance on Google Scholar. }\end{array}$ & 1.47 & 0.96 \\
\hline Preferred est. & $\begin{array}{l}=1 \text { if the estimate is preferred by authors or is explicitly con- } \\
\text { sidered to be better; }-1 \text { if it is considered inferior. }\end{array}$ & -0.04 & 0.47 \\
\hline Byproduct & $\begin{array}{l}=1 \text { if estimation of the elasticity is not the central focus of } \\
\text { the paper but only a byproduct; }=0 \text { if it is the central focus; } \\
=0.5 \text { if it is one of multiple main aims. }\end{array}$ & 0.20 & 0.31 \\
\hline
\end{tabular}


Table C1: Definitions and summary statistics of explanatory variables (continued)

\begin{tabular}{|c|c|c|c|}
\hline Variable & Description & Mean & Std. dev. \\
\hline \multicolumn{4}{|c|}{ Measurement of variables } \\
\hline$y:$ index & $=1$ if the input data for total output is in an index form. & 0.03 & 0.18 \\
\hline y: other & $\begin{array}{l}=1 \text { if the input data for total output is measured differently } \\
\text { than in gross domestic product or total value added (reference } \\
\text { category: GDP, value added). }\end{array}$ & 0.07 & 0.26 \\
\hline \multicolumn{4}{|l|}{ Labor-related } \\
\hline Quality adj. & $\begin{array}{l}=1 \text { if the input data for labor incomes data are quality- } \\
\text { adjusted. }\end{array}$ & 0.22 & 0.41 \\
\hline Self empl. & $\begin{array}{l}=1 \text { if the input data for labor incomes data are adjusted for } \\
\text { the income of self-employed people. }\end{array}$ & 0.18 & 0.39 \\
\hline w: nominal & $\begin{array}{l}=1 \text { if the input data for the wage rate are nominal (reference } \\
\text { category: the wage rate is in real terms). }\end{array}$ & 0.09 & 0.29 \\
\hline $\mathrm{w}$ : direct & $\begin{array}{l}=1 \text { if the input data for the wage rate are measured directly } \\
\text { (the wage rate calculated as total wages divided by the total } \\
\text { number of employees). }\end{array}$ & 0.14 & 0.36 \\
\hline L: hours & $=1$ if the input data for the labor are measured in hours. & 0.25 & 0.44 \\
\hline $\mathrm{L}:$ years & $=1$ if the input data for the labor are measured in years. & 0.07 & 0.25 \\
\hline L: FTE workers & $\begin{array}{l}=1 \text { if the input data for labor are measured by the full-time } \\
\text { equivalent number of workers. }\end{array}$ & 0.07 & 0.25 \\
\hline L: force & $\begin{array}{l}=1 \text { if number of workers labor is measured as the total number } \\
\text { of people in the labor force. }\end{array}$ & 0.04 & 0.20 \\
\hline \multicolumn{4}{|l|}{ Capital-related } \\
\hline Capacity adj. & $\begin{array}{l}=1 \text { if the authors control for the capacity utilization in the } \\
\text { regression. }\end{array}$ & 0.09 & 0.28 \\
\hline r: quasi & $\begin{array}{l}=1 \text { if the input data for the rental rate of capital are measured } \\
\text { as the quasi-rent, i.e., total output minus total wages divided } \\
\text { by total capital stock (reference category: it is measured as } \\
\text { the user cost of capital, Hall-Jorgenson formula). }\end{array}$ & 0.24 & 0.43 \\
\hline r: nominal & $\begin{array}{l}=1 \text { if the input data for the rental rate of capital are expressed } \\
\text { in nominal terms. }\end{array}$ & 0.01 & 0.09 \\
\hline K: IT & $=1$ if IT capital is used only. & 0.02 & 0.13 \\
\hline K: equipment & $=1$ if the measure of equipment capital is used only. & 0.07 & 0.26 \\
\hline K: structures & $=1$ if the measure of structures, land or plant is used only. & 0.04 & 0.17 \\
\hline $\mathrm{K}$ : residential & $=1$ if the measure of capital includes residential capital stock. & 0.07 & 0.25 \\
\hline K: services & $=1$ if capital is measured as service flow. & 0.13 & 0.33 \\
\hline K: perpetual & $\begin{array}{l}=1 \text { if the input data for capital is measured via perpetual } \\
\text { inventory method. }\end{array}$ & 0.36 & 0.48 \\
\hline K: index & $\begin{array}{l}=1 \text { if the input data for capital are expressed in an index } \\
\text { form. }\end{array}$ & 0.17 & 0.37 \\
\hline \multicolumn{4}{|l|}{ Industry-related } \\
\hline Primary ind. & $=1$ if the elasticity is estimated for the primary sector. & 0.02 & 0.14 \\
\hline Secondary ind. & $=1$ if the elasticity is estimated for the secondary sector. & 0.62 & 0.49 \\
\hline Tertiary ind. & $=1$ if the elasticity is estimated for the tertiary sector. & 0.03 & 0.18 \\
\hline Materials & $\begin{array}{l}=1 \text { if the elasticity is estimated for the } 2 \text {-digit industry in the } \\
\text { category "Materials" of the GICS industry classification. }\end{array}$ & 0.25 & 0.43 \\
\hline Industrials & $\begin{array}{l}=1 \text { if the elasticity is estimated for the } 2 \text {-digit industry in the } \\
\text { category "Industrials" of the GICS industry classification. }\end{array}$ & 0.09 & 0.29 \\
\hline Consumer & $\begin{array}{l}=1 \text { if the elasticity is estimated for the } 2 \text {-digit industry in the } \\
\text { category "Consumer goods" of the GICS industry classifica- } \\
\text { tion. }\end{array}$ & 0.14 & 0.34 \\
\hline
\end{tabular}

Note: Collected from published studies estimating the elasticity of substitution between capital and labor. When dummy variables form groups, we mention the reference category. 


\section{Appendix D Robustness Checks (for Online Publication)}

Table D1: Results of frequentist model averaging

\begin{tabular}{|c|c|c|c|}
\hline & Coef. & Std. er. & $p$-value \\
\hline Standard error & 0.557 & 0.042 & 0.000 \\
\hline \multicolumn{4}{|l|}{ Data characteristics } \\
\hline No. of obs. & 0.011 & 0.012 & 0.326 \\
\hline Midpoint & 0.103 & 0.022 & 0.000 \\
\hline Cross-sec. & 0.069 & 0.029 & 0.016 \\
\hline Panel & 0.193 & 0.042 & 0.000 \\
\hline Quarterly & 0.135 & 0.042 & 0.001 \\
\hline Firm data & -0.160 & 0.040 & 0.000 \\
\hline Industry data & -0.198 & 0.026 & 0.000 \\
\hline Country: US & 0.121 & 0.031 & 0.000 \\
\hline Country: Eur & 0.180 & 0.030 & 0.000 \\
\hline Developing & 0.019 & 0.019 & 0.333 \\
\hline Database: ASM,CM & -0.031 & 0.037 & 0.402 \\
\hline Database: OECD & -0.301 & 0.044 & 0.000 \\
\hline Database: KLEM & -0.092 & 0.046 & 0.047 \\
\hline Disaggregated $\sigma$ & 0.043 & 0.024 & 0.077 \\
\hline \multicolumn{4}{|l|}{ Specification } \\
\hline System PF+FOC & -0.111 & 0.059 & 0.061 \\
\hline System FOCs & -0.057 & 0.050 & 0.258 \\
\hline Nonlinear & -0.016 & 0.061 & 0.796 \\
\hline Linear approx. & 0.268 & 0.050 & 0.000 \\
\hline FOC_L_w & 0.324 & 0.032 & 0.000 \\
\hline FOC_KL_rw & 0.007 & 0.032 & 0.832 \\
\hline FOC_K_share & 0.226 & 0.063 & 0.000 \\
\hline FOC_L_share & 0.251 & 0.048 & 0.000 \\
\hline Cross-eq. restr. & 0.071 & 0.048 & 0.140 \\
\hline Normalized & -0.248 & 0.051 & 0.000 \\
\hline Two-level PF & -0.023 & 0.070 & 0.743 \\
\hline Partial sigma & 0.130 & 0.055 & 0.018 \\
\hline User cost. elast. & -0.373 & 0.042 & 0.000 \\
\hline \multicolumn{4}{|l|}{ Econometric approach } \\
\hline Dynamic est. & -0.005 & 0.029 & 0.854 \\
\hline SUR & -0.105 & 0.032 & 0.001 \\
\hline Identification & 0.046 & 0.026 & 0.077 \\
\hline Differenced & -0.096 & 0.027 & 0.000 \\
\hline Time FE & -0.009 & 0.040 & 0.830 \\
\hline Unit FE & 0.067 & 0.043 & 0.116 \\
\hline Short-run & -0.410 & 0.040 & 0.000 \\
\hline Long-run unadj. & -0.011 & 0.026 & 0.681 \\
\hline \multicolumn{4}{|c|}{ Production function components } \\
\hline Other inputs in PF & -0.137 & 0.044 & 0.002 \\
\hline CATC & -0.003 & 0.026 & 0.904 \\
\hline LATC & -0.041 & 0.024 & 0.088 \\
\hline Skilled L & 0.076 & 0.059 & 0.199 \\
\hline Constant TC growth & -0.032 & 0.025 & 0.191 \\
\hline Other TC growth & 0.108 & 0.035 & 0.002 \\
\hline No CRS & -0.003 & 0.022 & 0.905 \\
\hline No full comp. & -0.022 & 0.042 & 0.598 \\
\hline Net sigma & -0.320 & 0.056 & 0.000 \\
\hline \multicolumn{4}{|c|}{ Publication characteristics } \\
\hline Top journal & -0.085 & 0.025 & 0.001 \\
\hline Pub. year & 0.032 & 0.015 & 0.038 \\
\hline Citations & 0.037 & 0.011 & 0.001 \\
\hline Preferred & 0.027 & 0.016 & 0.093 \\
\hline Byproduct & -0.130 & 0.032 & 0.000 \\
\hline (Intercept) & -0.123 & 0.130 & 0.342 \\
\hline Observations & 3,186 & & \\
\hline
\end{tabular}

Notes: Our frequentist model averaging (FMA) exercise employs Mallow's weights (Hansen |2007) and the orthogonalization of the covariate space suggested by Amini \& Parmeter (2012). Dark gray color denotes variables that are deemed important also in the BMA exercise. Light gray color denote variables that are deemed important in the FMA but not BMA exercise. 
Figure D1: Model inclusion in Bayesian model averaging, weighted by the inverse of the number of estimates per study

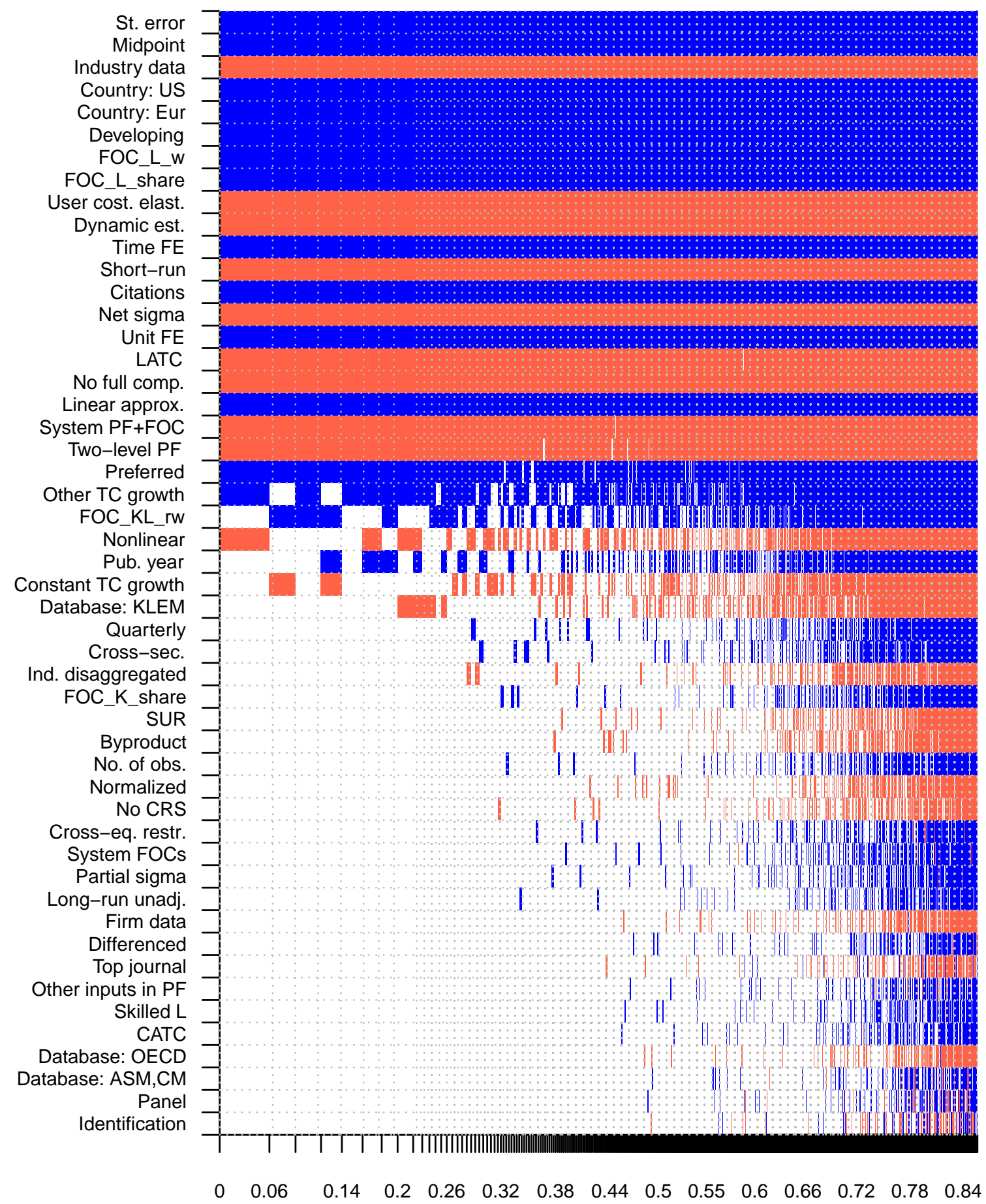

Notes: The response variable is the estimate of the elasticity of substitution. Columns denote individual models; variables are sorted by posterior inclusion probability in descending order. The horizontal axis denotes cumulative posterior model probabilities; only the 5,000 best models are shown. Blue color (darker in grayscale) $=$ the variable is included and the estimated sign is positive. Red color (lighter in grayscale) $=$ the variable is included and the estimated sign is negative. No color $=$ the variable is not included in the model 
Figure D2: Model inclusion in Bayesian model averaging, weighted by the inverse of the standard error

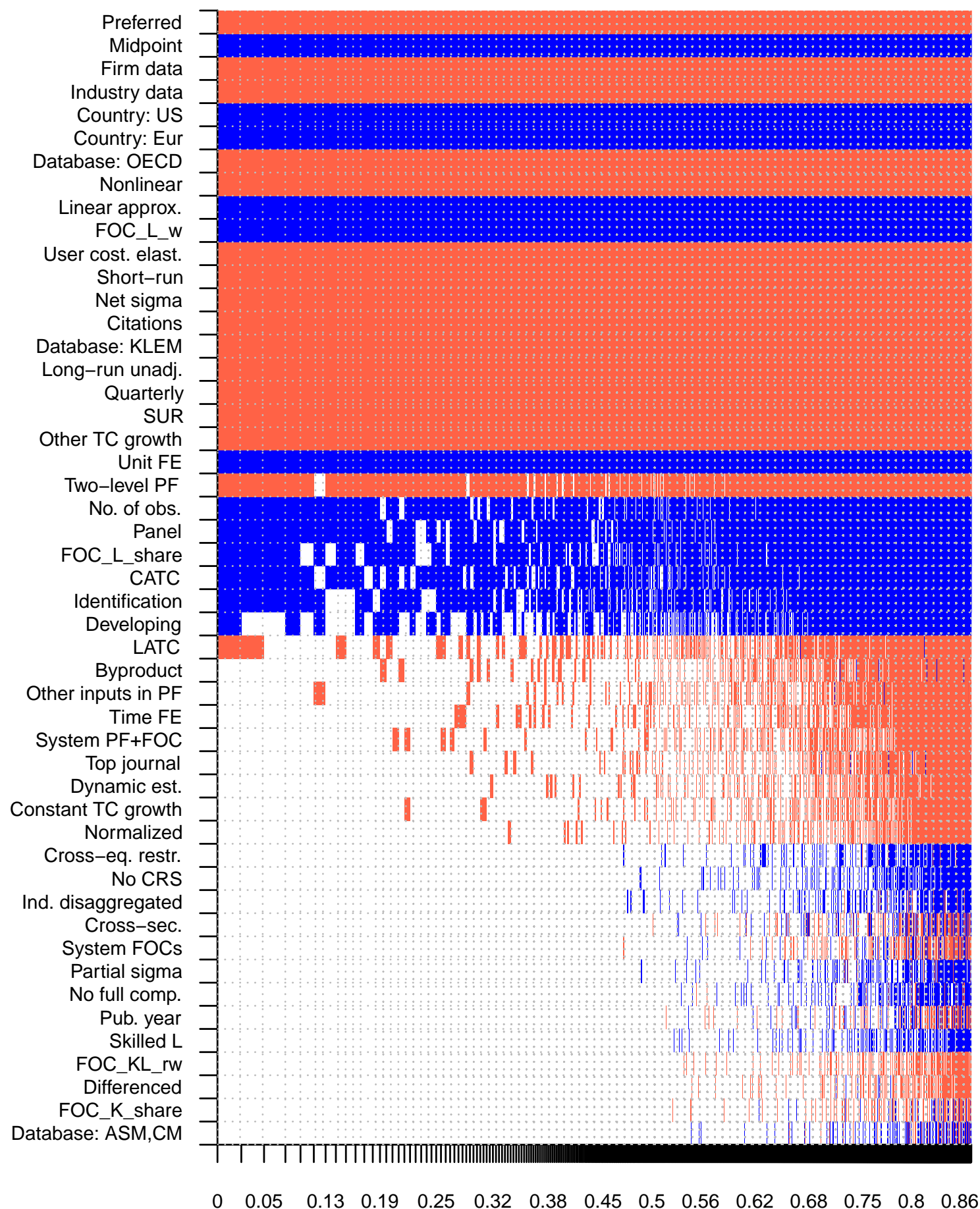

Notes: The response variable is the estimate of the elasticity of substitution. Columns denote individual models; variables are sorted by posterior inclusion probability in descending order. The horizontal axis denotes cumulative posterior model probabilities; only the 5,000 best models are shown. Blue color (darker in grayscale) $=$ the variable is included and the estimated sign is positive. Red color (lighter in grayscale) $=$ the variable is included and the estimated sign is negative. No color $=$ the variable is not included in the model. 


\section{Subsamples with measurement variables}

As a complementary exercise to our baseline specification, we also run BMA analyses for subsamples of data in order to control for variables that are relevant only for a given subsample. We call these variables measurement variables. We need to create subsamples of the main dataset, because the variables relevant for the FOC for labor are not relevant for the FOC for capital, and vice versa. Regarding the estimates that utilize the FOC for labor, we include additional variables on how labor and the wage rate are measured. Regarding the estimates that utilize the FOC for capital, we include variables on how capital and the rental rate of capital are measured. Regarding industry-level estimates, we include the sector for which the elasticity was estimated, that is, primary, secondary and tertiary sectors; and, within the secondary sector, groups for industrial goods production, material goods production, and consumer goods production.

Concerning the measurement of labor, our reference category is measurement via the number of workers. We include a dummy equal to one if labor is measured using the number of hours worked. We also include a dummy variable that equals one if labor income is adjusted for selfemployed labor income. As for the wage rate, we include dummy variables for the case when the rate is measured directly (in contrast to the situation when the wage rate is measured as the total amount paid to employees divided by the labor variable) and when the wage rate is used in nominal terms. In addition, we examine the effect of adjusting for changes in skill over time, for example, adjusting for the share of white- versus blue-collar workers.

Concerning the measurement of capital, our reference category is unspecified capital. We include dummies for specific measurements, including measurement as service flow, measurement via the perpetual inventory method, and capital stock in an index form. We code for special categories of capital stock: equipment, structures, IT, and residential capital stock. We include a separate dummy equal to one if the study controls for capacity utilization, either by adjusting the measurement variables or by adding it as a control. Underutilized capital would bias the results since it biases the effect of input on output (Brown, 1966); nevertheless, only a small portion of studies (Brown, 1966, Behrman, 1972, Dissou et al., 2015, among others) explicitly use this approach, for example by including capacity utilization indices.

Regarding the rental rate of capital, the baseline category comprises the user cost of capital, or, in other words, the standard Hall-Jorgenson formula (Jorgenson, 1963, Hall \& Jorgenson, 1967), which appears in two-thirds of all the estimations. The Hall-Jorgenson formula calculates the user cost of capital as a function of the relative price of capital, rate of return, and depreciation. We include a dummy for the case when the tax rate is an additional variable in the Hall-Jorgenson formula. The second most frequently used measurement is the quasi-rent approach, which calculates the rental rate of capital as a difference between total value added and total wages divided by the capital stock; this approach is used in $17 \%$ of the cases, for example in Dhrymes (1965), Ferguson (1965), and Lovell (1973). Further, the rental rate of capital can be measured either in gross terms or in net terms and in real or nominal terms; nevertheless, the variability in nominal user cost is almost zero, and thus we do not include the corresponding variable. 
In all subsamples we control for the measurement of output: first, we include a dummy variable that equals one if output is not measured as gross product or in value added terms, but in another way - for example, as the amount of sales. Second, we include a dummy for the case when output is used in an index form.

How does the addition of these variables affect our results? First, we include labor-specific variables, which capture how labor and wage rate are measured, and run BMA on the subsample of data estimating the FOC for labor. The subsample covers less than half of the original dataset; the results are displayed in Figure D3. Only two of the newly included measurement variables are important for the explanation of the heterogeneity in the reported elasticities: direct measurement of the wage rate and measurement of labor as total labor force. The main drivers of heterogeneity remain the same while the total explanatory power of the analysis increases only marginally.

Concerning capital-related variables, we find that the type of capital under examination represents an important driver of the differences in results (Figure D4). IT capital and equipment capital are more substitutable with labor than other types of capital, such as buildings. When capital is measured as service flow, the estimates typically yield a larger elasticity of substitution. It also matters how the rental rate of capital, $r$, is computed, specifically whether the Hall-Jorgenson formula is used - we find that it yields smaller elasticities than do other approaches. The best-practice estimate derived from both subsamples and conditional on plugging in mean values for measurement variables would again equal 0.3, very far from the Cobb-Douglas assumption.

Finally, for the subsample of disaggregated elasticities we run the baseline BMA enriched with industry-relevant variables in Figure D5. We do not find any significant determinants that would suggest that the elasticity of capital-labor substitution differs systematically across sectors or industry groups (production of materials, production of industrial goods, production of consumer goods, and production of services). Given the number of variables in our analysis, it is infeasible to add more industry-specific variables since that would create troubles with collinearity. 
Figure D3: Model inclusion in Bayesian model averaging, labor-specific variables

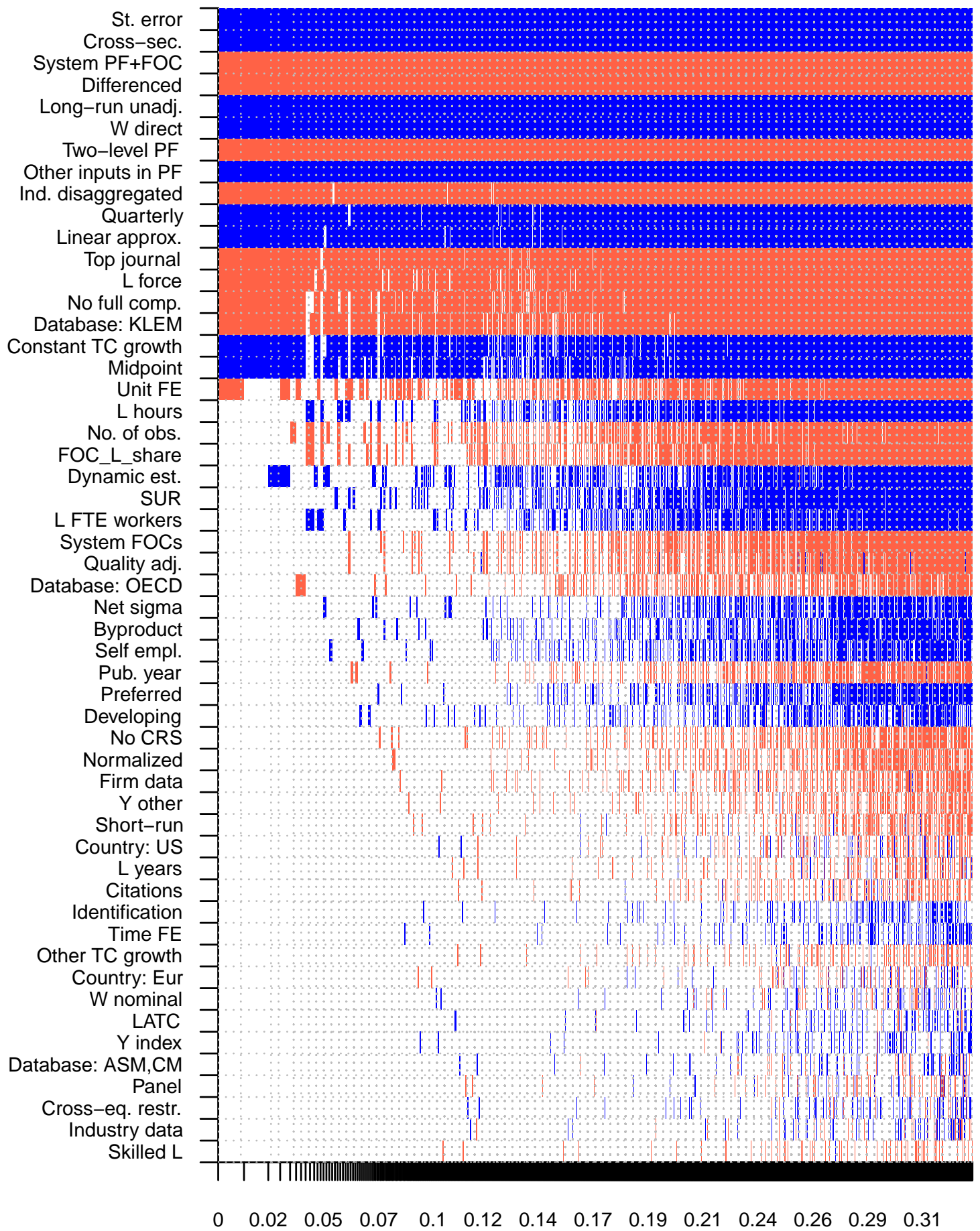

Notes: The response variable is the estimate of the elasticity of substitution. Columns denote individual models; variables are sorted by posterior inclusion probability in descending order. The horizontal axis denotes cumulative posterior model probabilities; only the 5,000 best models are shown. Blue color (darker in grayscale) $=$ the variable is included and the estimated sign is positive. Red color (lighter in grayscale) $=$ the variable is included and the estimated sign is negative. No color $=$ the variable is not included in the model 
Figure D4: Model inclusion in Bayesian model averaging, capital-specific variables

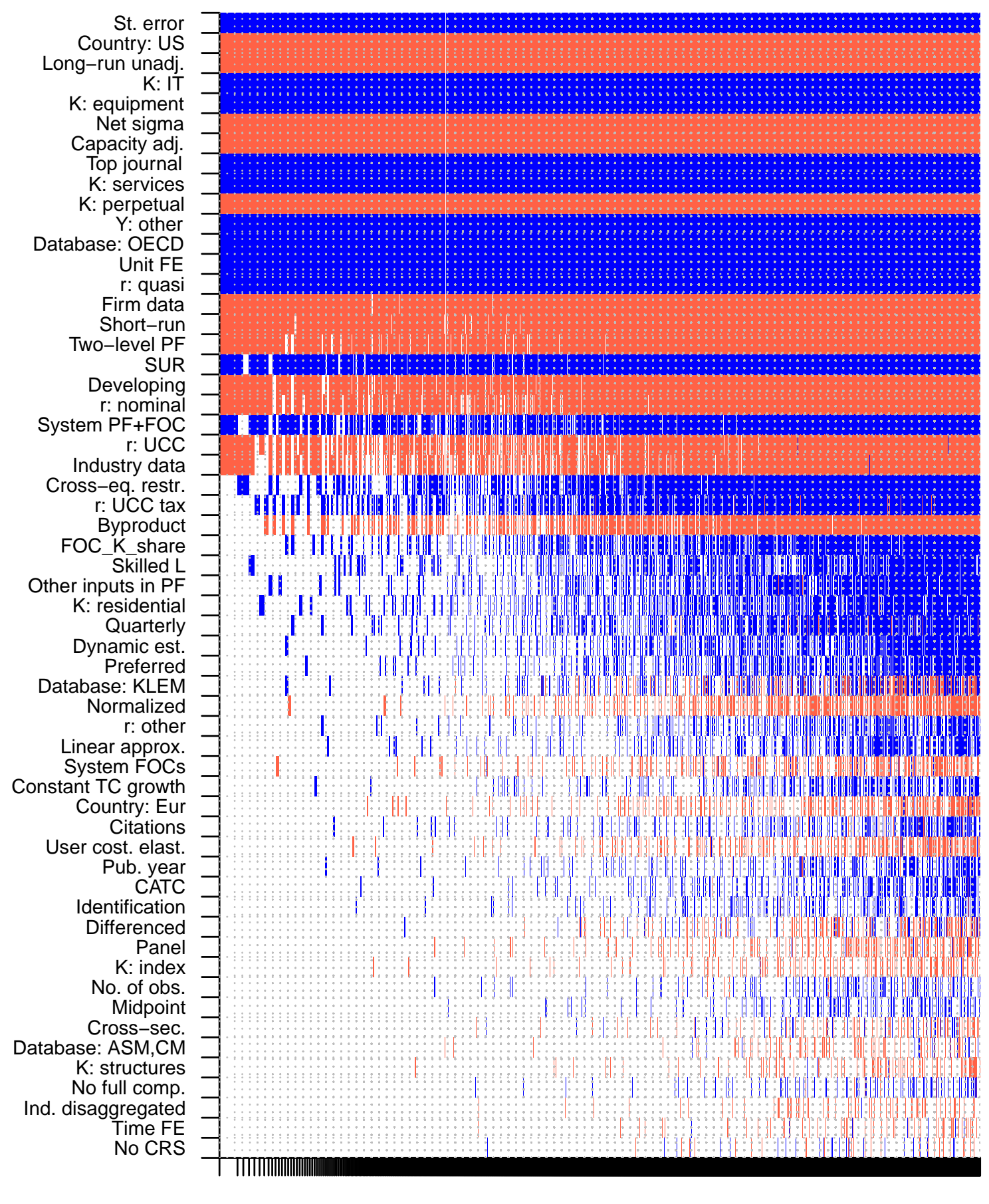

Notes: The response variable is the estimate of the elasticity of substitution. Columns denote individual models; variables are sorted by posterior inclusion probability in descending order. The horizontal axis denotes cumulative posterior model probabilities; only the 5,000 best models are shown. Blue color (darker in grayscale) $=$ the variable is included and the estimated sign is positive. Red color (lighter in grayscale) $=$ the variable is included and the estimated sign is negative. No color $=$ the variable is not included in the model 
Figure D5: Model inclusion in Bayesian model averaging, industry-specific variables

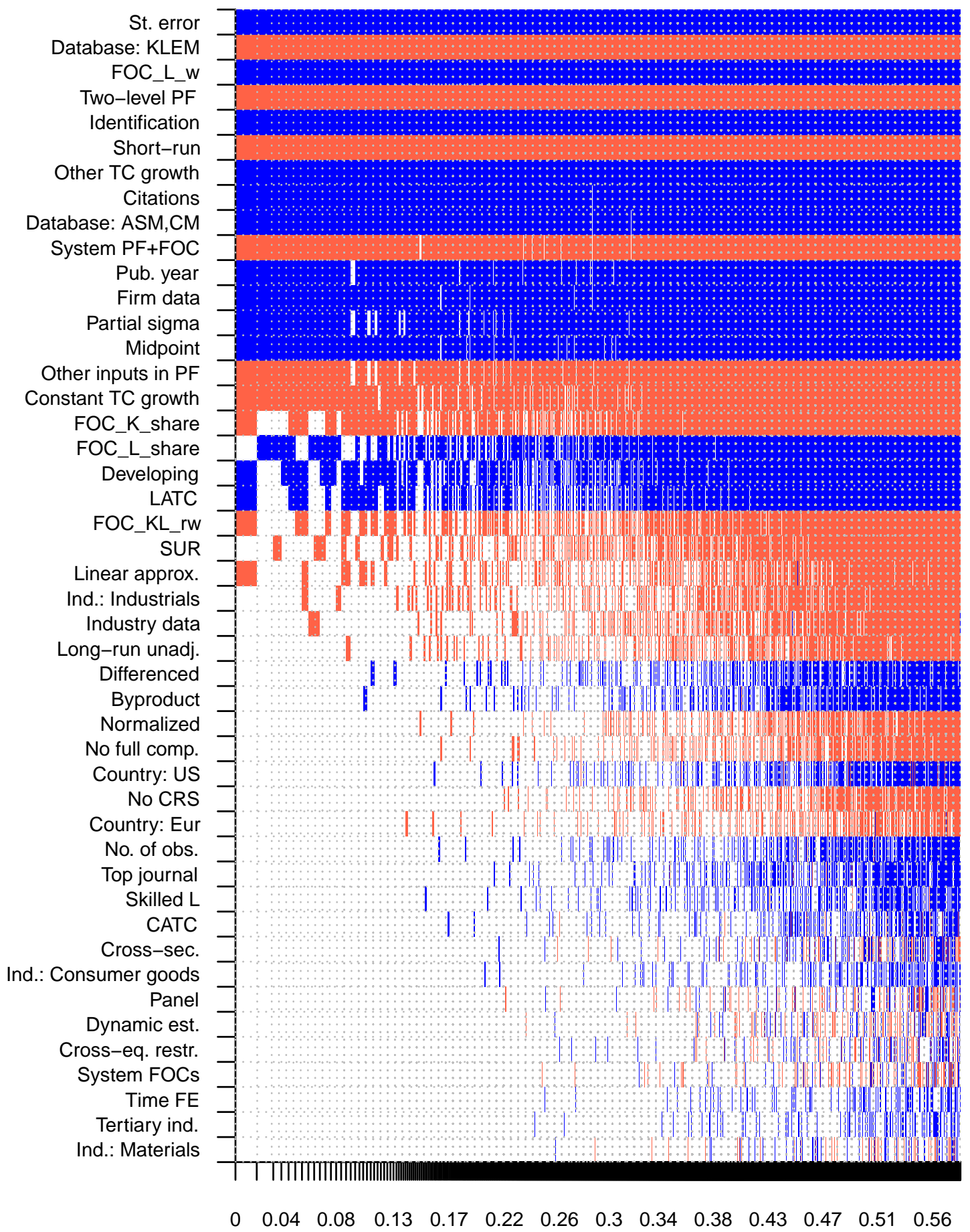

Notes: The response variable is the estimate of the elasticity of substitution. Columns denote individual models; variables are sorted by posterior inclusion probability in descending order. The horizontal axis denotes cumulative posterior model probabilities; only the 5,000 best models are shown. Blue color (darker in grayscale) $=$ the variable is included and the estimated sign is positive. Red color (lighter in grayscale) $=$ the variable is included and the estimated sign is negative. No color $=$ the variable is not included in the model 


\section{Appendix E Studies Included in the Dataset (for Online Pub- lication)}

ABeD, G. T. (1975): "Labour Absorption in Industry: An Analysis with Reference to Egypt." Oxford Economic Papers 27(3): pp. 400-425.

Akay, G. H. \& C. Dogan (2013): "The Effect of Labor Supply Changes on Output: Empirical Evidence from US Industries." Journal of Productivity Analysis 39(2): pp. 123-130.

Antras, P. (2004): "Is the US Aggregate Production Function Cobb-Douglas? New Estimates of the Elasticity of Substitution." Contributions in Macroeconomics 4(1): pp. 1-36.

Apostolakis, B. E. (1984): "A Translogarithmic Cost Function Approach: Greece, 1953-1977." Empirical Economics 9(4): pp. 247-262.

Arrow, K. J., H. B. Chenery, B. S. Minhas, \& R. M. Solow (1961): "Capital-Labor Substitution and Economic Efficiency." Review of Economics and Statistics 43(3): pp. 225-250.

Artus, J. R. (1984): "The Disequilibrium Real Wage Rate Hypothesis: An Empirical Evaluation." Staff Papers 31(2): pp. 249-302.

Asher, E. (1972): "Industrial Efficiency and Biased Technical Change in American and British Manufacturing: The Case of Textiles in the Nineteenth Century." Journal of Economic History 32(2): pp. 431-442.

Balistreri, E. J., C. A. McDaniel, \& E. V. WONG (2003): "An Estimation of US Industry-Level Capital-Labor Substitution Elasticities: Support for Cobb-Douglas." North American Journal of Economics and Finance 14(3): pp. 343-356.

Bartelsman, E. J. \& R. M. Beetsma (2003): "Why Pay More? Corporate Tax Avoidance through Transfer Pricing in OECD Countries." Journal of Public Economics 87(9-10): pp. 2225-2252.

Behrman, J. (1982): "Country and Sectoral Variations in Manufacturing Elasticities of Substitution between Capital and Labor." In "Trade and Employment in Developing Countries, Volume 2: Factor Supply and Substitution," pp. 159-192. University of Chicago.

Behrman, J. R. (1972): "Sectoral Elasticities of Substitution between Capital and Labor in a Developing Economy: Times Series Analysis in the Case of Postwar Chile." Econometrica 40(2): pp. 311-326.

Bentolila, S. \& G. Saint-Paul (2003): "Explaining Movements in the Labor Share." Contributions in Macroeconomics 3(1): pp. 1-33.

Berndt, E. R. (1976): "Reconciling Alternative Estimates of the Elasticity of Substitution." Review of Economics and Statistics 58(1): pp. 59-68.

Berthold, N., R. Fehn, \& E. Thode (2002): "Falling Labor Share and Rising Unemployment: Long-Run Consequences of Institutional Shocks?" German Economic Review 3(4): pp. 431-459.

Binswanger, H. P. (1974): "A Cost Function Approach to the Measurement of Elasticities of Factor Demand and Elasticities of Substitution." American Journal of Agricultural Economics 56(2): pp. 377-386.

Blanchard, O. J. (1997): "The Medium Run." Brookings Papers on Economic Activity 1997(2): pp. 89141.

Bodkin, R. G. \& L. R. Klein (1967): "Nonlinear Estimation of Aggregate Production Functions." Review of Economic and Statistics 49(1): pp. 28-44.

Brown, M. (1966): "A Measure of the Change in Relative Exploitation of Capital and Labor." Review of Economics and Statistics 48(2): pp. 182-192.

Brown, M. \& J. S. De CANi (1963): "Technological Change and the Distribution of Income." International Economic Review 4(3): pp. 289-309.

Brox, J. A. \& C. A. FAder (2005): "Infrastructure Investment and Canadian Manufacturing Productivity." Applied Economics 37(11): pp. 1247-1256.

Bruno, M. \& J. SAChs (1982): "Input Price Shocks and the Slowdown in Economic Growth: The Case of UK Manufacturing." Review of Economic Studies 49(5): pp. 679-705.

Caballero, R. J. (1994): "Small Sample Bias and Adjustment Costs." Review of Economics and Statistics 76(1): pp. $52-58$.

Chetty, V. K. \& U. SAnkar (1969): "Bayesian Estimation of the CES Production Function." Review of Economic Studies 36(3): pp. 289-294.

Chirinko, R. S., S. M. Fazzari, \& A. P. Meyer (1999): "How Responsive Is Business Capital Formation to its User Cost? An Exploration with Micro Data." Journal of Public Economics 74(1): pp. 53-80.

Chirinko, R. S., S. M. Fazzari, \& A. P. Meyer (2011): "A New Approach to Estimating Production Function Parameters: The Elusive Capital-Labor Substitution Elasticity." Journal of Business $\&$ Economic Statistics 29(4): pp. 587-594.

Chirinko, R. S. \& D. Mallick (2017): "The Substitution Elasticity, Factor Shares, and the LowFrequency Panel Model." American Economic Journal: Macroeconomics 9(4): pp. 225-53.

Chwelos, P., R. Ramirez, K. L. Kraemer, \& N. P. Melville (2010): "Does Technological Progress Alter the Nature of Information Technology as a Production Input? New Evidence and New Results." Information Systems Research 21(2): pp. 392-408.

Clark, P. K. \& D. E. Sichel (1993): "Tax Incentives and Equipment Investment." Brookings Papers on 
Economic Activity 1993(1): pp. 317-347.

Claro, S. (2003): "A Cross-Country Estimation of the Elasticity of Substitution between Labor and Capital in Manufacturing Industries." Cuadernos de economía 40(120): pp. 239-257.

Cummins, J. G. \& K. A. Hassett (1992): "The Effects of Taxation on Investment: New Evidence from Firm Level Panel Data." National Tax Journal 45(3): pp. 243-251.

Cummins, J. G., K. A. Hassett, R. G. Hubbard, R. E. Hall, \& R. J. Caballero (1994): "A Reconsideration of Investment Behavior Using Tax Reforms as Natural Experiments." Brookings Papers on Economic Activity 1994(2): pp. 1-74.

DANiELS, M. R. (1969): "Differences in Efficiency among Industries in Developing Countries." American Economic Review 59(1): pp. 159-171.

David, P. A. \& T. VAn de Klundert (1965): "Biased Efficiency Growth and Capital-Labor Substitution in the US, 1899-1960." American Economic Review 55(3): pp. 357-394.

Dhrymes, P. J. (1965): "Some Extensions and Tests for the CES Class of Production Functions." Review of Economics and Statistics 47(4): pp. 357-366.

Dissou, Y. \& R. Ghazal (2010): "Energy Substitutability in Canadian Manufacturing Econometric Estimation with Bootstrap Confidence Intervals." Energy Journal 31(1): pp. 121-148.

Dissou, Y., L. Karnizova, \& Q. Sun (2015): "Industry-Level Econometric Estimates of EnergyCapital-Labor Substitution with a Nested CES Production Function." Atlantic Economic Journal 43(1): pp. 107-121.

Donges, J. B. (1972): "Returns to Scale and Factor Substitutability in the Spanish Industry." Review of World Economics 108(4): pp. 597-608.

Duffy, J. \& C. Papageorgiou (2000): "A CrossCountry Empirical Investigation of the Aggregate Production Function Specification." Journal of Economic Growth 5(1): pp. 87-120.

Dwenger, N. (2014): "User Cost Elasticity of Capital Revisited." Economica 81(321): pp. 161-186.

EAsterly, W. \& S. Fischer (1995): "The Soviet Economic Decline." World Bank Economic Review 9(3): pp. 341-371.

EIsneR, R. (1967): "Capital and Labor in Production: Some Direct Estimates." In "The Theory and Empirical Analysis of Production," pp. 431-475. NBER.

Eisner, R. (1969): "Tax Policy and Investment Behavior: Comment." American Economic Review 59(3): pp. $379-388$.

EISNER, R. \& M. I. NADIRI (1968): "Investment Behavior and Neo-Classical Theory." Review of Economics and Statistics 50(3): pp. 369-382.

Elbers, C., J. W. Gunning, \& B. Kinsey (2007): "Growth and Risk: Methodology and Micro Evi- dence." World Bank Economic Review 21(1): pp. $1-20$.

Ellis, C. \& S. PRICE (2004): "UK Business Investment and the User Cost of Capital." Manchester School 72: pp. 72-93.

Feldstein, M. S. (1967): "Specification of the Labour Input in the Aggregate Production Function." Review of Economic Studies 34(4): pp. 375-386.

Feldstein, M. S. \& J. S. Flemming (1971): "Tax Policy, Corporate Saving and Investment Behaviour in Britain." Review of Economic Studies 38(4): pp. 415-434.

Felipe, J. \& J. MCCombie (2009): "Are Estimates of Labour Demand Functions Mere Statistical Artefacts?" International Review of Applied Economics 23(2): pp. 147-168.

Ferguson, C. E. (1965): "Time-Series Production Functions and Technological Progress in American Manufacturing Industry." Journal of Political Economy 73(2): pp. 135-147.

Fishelson, G. (1979): "Elasticity of Factor Substitution in Cross-Section Production Functions." Review of Economics and Statistics 61(3): pp. 432-436.

Fitchetт, D. A. (1976): "Capital-Labor Substitution in the Manufacturing Sector of Panama." Economic Development and Cultural Change 24(3): pp. 577592.

Fuchs, V. R. (1963): "Capital-Labor Substitution: A Note." Review of Economics and Statistics 45(4): pp. $436-438$.

Griliches, Z. (1964): "Research Expenditures, Education, and the Aggregate Agricultural Production Function." American Economic Review 54(6): pp. 961-974.

Griliches, Z. (1967): "Production Functions in Manufacturing: Some Preliminary Results." In "The Theory and Empirical Analysis of Production," pp. 275340. NBER.

Herrendorf, B., C. Herrington, \& A. Valentinyi (2015): "Sectoral Technology and Structural Transformation." American Economic Journal: Macroeconomics 7(4): pp. 104-33.

Hijzen, A. \& P. Swaim (2010): "Offshoring, Labour Market Institutions and the Elasticity of Labour Demand." European Economic Review 54(8): pp. 1016-1034.

Hossain, S. I. (1987): "Allocative and Technical Efficiency: A Study of Rural Enterprises in Bangladesh." Developing Economies 25(1): pp. 5672 .

Humphrey, D. B. \& J. R. Moroney (1975): "Substitution among Capital, Labor, and Natural Resource Products in American Manufacturing." Journal of Political Economy 83(1): pp. 57-82.

IQBAL, M. (1986): "Substitution of Labour, Capital and Energy in the Manufacturing Sector of Pakistan." Empirical Economics 11(2): pp. 81-95. 
Jalava, J., M. Pohjola, A. Ripatti, \& J. Vilmunen (2006): "Biased Technical Change and CapitalLabour Substitution in Finland, 1902-2003." Topics in Macroeconomics 6(1): pp. 1-20.

Jones, D. C. \& D. K. Backus (1977): "British Producer Cooperatives in the Footware Industry: An Empirical Evaluation of the Theory of Financing." Economic Journal 87(347): pp. 488-510.

JudziK, D. \& H. SAla (2015): "The Determinants of Capital Intensity in Japan and the US." Journal of the Japanese and International Economies 35: pp. 78-98.

Juselius, M. (2008): "Long-Run Relationships between Labor and Capital: Indirect Evidence on the Elasticity of Substitution." Journal of Macroeconomics 30(2): pp. 739-756.

Kalt, J. P. (1978): "Technological Change and Factor Substitution in the United States: 1929-1967." International Economic Review 19(3): pp. 761-775.

Karabarbounis, L. \& B. Neiman (2013): "The Global Decline of the Labor Share." Quarterly Journal of Economics 129(1): pp. 61-103.

Kilponen, J. \& M. Viren (2010): "Why Do Growth Rates Differ? Evidence from Cross-Country Data on Private Sector Production." Empirica 37(3): pp. 311-328.

Kislev, Y. \& W. Peterson (1982): "Prices, Technology, and Farm Size." Journal of Political Economy 90(3): pp. 578-595.

Klump, R., P. McAdam, \& A. Willman (2007): "Factor Substitution and Factor-Augmenting Technical Progress in the United States: A Normalized SupplySide System Approach." Review of Economics and Statistics 89(1): pp. 183-192.

Klump, R., P. McAdam, \& A. Willman (2008): "Unwrapping Some Euro Area Growth Puzzles: Factor Substitution, Productivity and Unemployment." Journal of Macroeconomics 30(2): pp. 645-666.

Kmenta, J. (1967): "On Estimation of the CES Production Function." International Economic Review 8(2): pp. 180-189.

Krusell, P., L. E. Ohanian, J.-V. Roos-Rull, \& G. L. Violante (2000): "Capital-Skill Complementarity and Inequality: A Macroeconomic Analysis." Econometrica 68(5): pp. 1029-1053.

LeE, M. \& M. Tcha (2004): "The Color of Money: The Effects of Foreign Direct Investment on Economic Growth in Transition Economies." Review of World Economics 140(2): pp. 211-229.

León-Ledesma, M. A., P. McAdam, \& A. Willman (2015): "Production Technology Estimates and Balanced Growth." Oxford Bulletin of Economics and Statistics 77(1): pp. 40-65.

Leung, D. \& T. Yuen (2010): "Do Exchange Rates Affect the Capital-Labour Ratio? Panel Evidence from Canadian Manufacturing Industries." Applied Economics 42(20): pp. 2519-2535.
LiAnos, T. P. (1971): "The Relative Share of Labor in United States Agriculture, 1949-1968." American Journal of Agricultural Economics 53(3): pp. 411-422.

LiAnos, T. P. (1975): "Capital-Labor Substitution in a Developing Country: The Case of Greece." European Economic Review 6(2): pp. 129-141.

Lin, W. T. \& B. B. Shao (2006): "The Business Value of Information Technology and Inputs Substitution: The Productivity Paradox Revisited." Decision Support Systems 42(2): pp. 493-507.

Lovell, C. K. (1973a): "CES and VES Production Functions in a Cross-Section Context." Journal of Political Economy 81(3): pp. 705-720.

Lovell, C. K. (1973b): "Estimation and Prediction with CES and VES Production Functions." International Economic Review 14(3): pp. 676-692.

Luoma, A. \& J. Luoto (2010): "The Aggregate Production Function of the Finnish Economy in the Twentieth Century." Southern Economic Journal 76(3): pp. 723-737.

Mallick, D. (2012): "The Role of the Elasticity of Substitution in Economic Growth: A Cross-Country Investigation." Labour Economics 19(5): pp. 682694.

Martin, S. A., R. McHugh, \& S. R. Johnson (1993): "The Influence of Location on Productivity: Manufacturing Technology in Rural and Urban Areas." Growth and Change 24(4): pp. 459-486.

Masanjala, W. H. \& C. Papageorgiou (2004): "The Solow Model with CES Technology: Nonlinearities and Parameter Heterogeneity." Journal of Applied Econometrics 19(2): pp. 171-201.

McAdam, P. \& A. Willman (2004): "Production, Supply and Factor Shares: An Application to Estimating German Long-Run Supply." Economic Modelling 21(2): pp. 191-215.

McCallum, J. (1985): "Wage Gaps, Factor Shares and Real Wages." Scandinavian Journal of Economics 87(2): pp. 436-459.

McKinnon, R. I. (1962): "Wages, Capital Costs, and Employment in Manufacturing: A Model Applied to 1947-58 US Data." Econometrica 30(3): pp. 501521.

McLean-Meyinsse, P. E. \& A. A. Okunade (1988): "Factor Demands of Louisiana Rice Producers: An Econometric Investigation." Journal of Agricultural and Applied Economics 20(2): pp. 127-136.

Meller, P. (1975): "Production Functions for Industrial Establishments of Different Sizes: The Chilean Case." In "Annals of Economic and Social Measurement, Volume 4, number 4," pp. 595-634. NBER.

Minasian, J. R. (1961): "Elasticities of Substitution and Constant-Output Demand Curves for Labor." Journal of Political Economy 69(3): pp. 261-270.

Mohabbat, K. A. \& A. J. Dalai (1983): "Factor Substitution and Import Demand for South Korea: A 
Translog Analysis." Review of World Economics 119(4): pp. 709-723.

Mohabbat, K. A., A. Dalal, \& M. Williams (1984): "Import Demand for India: A Translog Cost Function Approach." Economic Development and Cultural Change 32(3): pp. 593-605.

Moroney, J. R. (1966): "Time-Series Elasticities of Substitution and Labor's Share in US Manufacturing: The Postwar Period." Southern Economic Journal 32(4): p. 474.

Moroney, J. R. (1970): "Identification and Specification Analysis of Alternative Equations for Estimating the Elasticity of Substitution." Southern Economic Journal 36(3): pp. 287-299.

Moroney, J. R. \& B. T. Allen (1969): "Monopoly Power and the Relative Share of Labor." ILR Review 22(2): pp. 167-178.

Moroney, J. R. \& A. L. Toevs (1977): "Factor Costs and Factor Use: An Analysis of Labor, Capital, and Natural Resource Inputs." Southern Economic Journal 44(2): pp. 222-239.

NADIRI, M. I. (1968): “The Effects of Relative Prices and Capacity on the Demand for Labour in the US Manufacturing Sector." Review of Economic Studies 35(3): pp. 273-288.

PANIK, M. J. (1976): "Factor Learning and Biased Factor-Efficiency Growth in the United States, 19291966." International Economic Review 17(3): pp. 733-739.

PARKs, R. W. (1971): "Price Responsiveness of Factor Utilization in Swedish Manufacturing, 1870-1950." Review of Economics and Statistics 53(2): pp. 129139.

Pollak, R. A., R. C. Sickles, \& T. J. Wales (1984): "The CES-Translog: Specification and Estimation of a New Cost Function." Review of Economics and Statistics 66(4): pp. 602-607.

Raurich, X., H. Sala, \& V. Sorolla (2012): "Factor Shares, the Price Markup, and the Elasticity of Substitution between Capital and Labor." Journal of Macroeconomics 34(1): pp. 181-198.

Roskamp, K. W. (1977): "Labor Productivity and the Elasticity of Factor Substitution in West German Industries 1950-1960." Review of Economics and Statistics 59(3): pp. 366-371.

SAнотA, G. S. (1966): "The Sources of Measured Productivity Growth: United States Fertilizer Mineral Industries, 1936-1960." Review of Economics and Statistics 48(2): pp. 193-204.

Salvanes, K. G. (1989): "The Structure of the Norwegian Fish Farming Industry: An Empirical Analysis of Economies of Scale and Substitution Possibilities." Marine Resource Economics 6(4): pp. 349-373.

SANKAR, U. (1972): "Investment Behavior in the US Electric Utility Industry, 1949-1968." Bell Journal of Economics 3(2): pp. 645-664.

SAPIR, A. (1980): "Economic Growth and Factor Sub- stitution: What Happened to the Yugoslav Miracle?" Economic Journal 90(358): pp. 294-313.

SAto, K. (1977): "A note on Factor Substitution and Efficiency." Review of Economics and Statistics 59(3): pp. 360-366.

Sato, R. \& R. F. Hoffman (1968): "Production Functions with Variable Elasticity of Factor Substitution: Some Analysis and Testing." Review of Economics and Statistics 50(4): pp. 453-460.

Saxonhouse, G. (1977): "Productivity Change and Labor Absorption in Japanese Cotton Spinning 1891-1935." Quarterly Journal of Economics 91(2): pp. $195-219$

Schaller, H. (2006): "Estimating the Long-Run User Cost Elasticity." Journal of Monetary Economics 53(4): pp. $725-736$.

Schmitz, M. (1981): "The Elasticity of Substitution in 19th-Century Manufacturing." Explorations in Economic History 18(3): p. 290.

Semieniuk, G. (2017): "Piketty's Elasticity of Substitution: A Critique." Review of Political Economy 29(1): pp. 64-79.

Shahe Emran, M., F. Shilpi, \& M. I. Alam (2007): "Economic Liberalization and Price Response of Aggregate Private Investment: Time Series Evidence from India." Canadian Journal of Economics 40(3): pp. 914-934.

Smith, J. (2008): "That Elusive Elasticity and the Ubiquitous Bias: Is Panel Data a Panacea?" Journal of Macroeconomics 30(2): pp. 760-779.

Solow, R. (1964): "Capital, Labor, and Income in Manufacturing." In "The Behavior of Income Shares: Selected Theoretical and Empirical Issues," pp. 101142. Princeton University Press.

Tevlin, S. \& K. Whelan (2003): "Explaining the Investment Boom of the 1990s." Journal of Money, Credit and Banking 35(1): pp. 1-22.

Tsang, H. H. \& J. J. Persky (1975): "On the Empirical Content of CES Production Functions." Economic Record 51(4): pp. 539-548.

Weitzman, M. L. (1970): "Soviet Postwar Economic Growth and Capital-Labor Substitution." American Economic Review 60(4): pp. 676-692.

VAN DER Werf, E. (2008): "Production Functions for Climate Policy Modeling: An Empirical Analysis." Energy Economics 30(6): pp. 2964-2979.

Williams, M. \& P. S. Laumas (1984): "Economies of Scale for Various Types of Manufacturing Production Technologies in an Underdeveloped Economy." Economic Development and Cultural Change 32(2): pp. 401-412.

YounG, A. T. (2013): "US Elasticities of Substitution and Factor Augmentation at the Industry Level." Macroeconomic Dynamics 17(4): pp. 861-897.

ZarembKa, P. (1970): "On the Empirical Relevance of the CES Production Function." Review of Economics and Statistics 52(1): pp. 47-53. 